Archivum, LXIX, 2019, pp. 161-213

\title{
Sobre el diptongo ortográfico
}

\author{
SAlvador GutiérRez Ordóñez \\ Real Academia Española / Universidad de León \\ bimenes48@gmail.com
}

Recibido: 5/11/2019

Aceptado: 10/01/2020

\section{RESUMEN:}

La Ortografía de la lengua española $(R A E, 2010)$ define las nociones de diptongo e hiato, no con criterios fonéticos, sino con criterios ortográficos. A pesar de las críticas, esta decisión ha sido una gran aportación teórica y práctica. No solo ha tenido antecedentes, sino que se fundamenta en criterios fonológicos. La frontera morfológica no es relevante en la determinación ortográfica de los diptongos.

PALABRAS CLAVE: Ortografía, fonología, diptongo ortográfico, hiato ortográfico, frontera morfológica.

\section{About the orthographic diphthong}

\section{ABSTRACT:}

The Ortografía de la lengua española $(R A E, 2010)$ defines the notions of diphthong and hiatus, not with phonetic criteria, but with orthographic criteria. Despite the criticisms, this proposal has been a great theoretical and practical contribution; not only because it has had important precedents, but also because it is based on phonological criteria. The morphological frontier is not relevant in the orthographic determination of diphthongs.

KEYWORDS: Orthography, Phonology, orthographic diphthong, orthographic hiatus, morphological frontier. 


\section{Diptongo e hiato ortográficos ${ }^{1}$}

\subsection{Descripción}

Aunque la Ortografía de la lengua española de 1999 (OLE99) recoge las definiciones tradicionales de diptongo y de hiato (de naturaleza prosódica ${ }^{2}$ ), determina con criterio ortográfico cuáles de las combinaciones vocálicas del español forman diptongo (o triptongo) y cuáles constituyen hiato. Este cambio de criterio constituye una innovación de enorme trascendencia para la disciplina. Así describe las formas de combinación vocálica en las que se producen los diptongos a efectos de la escritura:

A efectos ortográficos, para que haya diptongo debe darse una de estas situaciones:

a) Que se sucedan una vocal abierta $(a, e, o)$ y una cerrada $(i, u)$, o viceversa, siempre que la cerrada no sea tónica. En consecuencia, son diptongos las siguientes combinaciones: $a i, a u, e i, e u, o i, o u, i a$, ie, io, ua, ue, uo. Ejemplos: aire, causa, peine, Ceuta, oiga, bou, viaje, ciego, quiosco, suave, fuerte, cuota.

b) Que se combinen dos vocales cerradas $(i, u)$ distintas: $u i, i u$. Ejemplos: ruido, diurético, etc. (OLE99: 43).

Siguiendo el mismo proceder, describe las combinaciones de vocales que forman hiato:

A efectos ortográficos, existen tres clases de hiatos, según el tipo de vocales que están en contacto:

a) Combinación de vocales iguales. Ejemplos: Saavedra, dehesa, chiita, Campoo, duunviro.

1 Este trabajo está enmarcado dentro del proyecto Macrosintaxis del Español Actual. El enunciado: estructura y relaciones (MESA), financiado por el Ministerio de Economía y Competitividad (FFI2013-43205-P) y dirigido por la Dra. Catalina Fuentes Rodríguez.

2 «Un diptongo es el conjunto de dos vocales que se pronuncian en una misma sílaba» (OLE99: 43); «Un hiato es la secuencia de dos vocales que no se pronuncian dentro de una misma sílaba, sino que forman parte de sílabas consecutivas. Ejemplos: te-a-tro, $a-e ́-r e-o, v i-g i ́-a, s a-l i ́-a s »(O L E 99: 45)$. La expresión se pronuncia muestra la naturaleza fonética de la definición. 
b) Vocal abierta + vocal abierta distintas. Ejemplos: caen, ahogo, teatro, meollo, héroe, coartada. [...].

c) Vocal abierta átona + vocal cerrada tónica o viceversa. Ejemplos: caímos, día, aúllan, reís, lié, reúnen (OLE99: 45).

\subsection{Causas del cambio de criterio}

¿Por qué la introducción de un nuevo criterio, diferente del fónico y prosódico? Porque la realización fonética de una misma secuencia vocálica ya como diptongo ya como hiato se halla sujeta a variaciones de distinto tipo: de situación geográfica, de registro, de velocidad elocutiva, de tipo de dicción, de posición en la frase, etc. Así marcaba la diferencia del criterio ortográfico frente al fonético (basado en la pronunciación):

Algunas de estas combinaciones vocálicas pueden articularse como hiatos (es decir, en dos sílabas), dependiendo de distintos factores: su lugar en la secuencia hablada, el mayor o menor esmero en la pronunciación, el origen geográfico o social de los hablantes, etc. Este es el caso, por ejemplo, de fluir (pronunciado fluir, con diptongo, o flu - ir, con hiato), de incluido (pronunciado in - clui - do, con diptongo, o in - clu $-i-d o$, con hiato), de cruel (pronunciado cruel o cru - el), de desviado (que se pronuncia des - via - do o des - vi - a do), etc.

Sin embargo, a efectos de la acentuación gráfica, se considerará siempre que se trata de diptongos (OLE99: 43).

\section{Antecedentes inmediatos}

2.1 Innovación. Esta innovación implicaba tres grados:

1. Conocimiento de que los diptongos ortográficos se articulan geográfica u ocasionalmente como hiatos y de que los hiatos en determinados lugares y circunstancias se pronuncian como diptongos ${ }^{3}$.

3 T. Navarro Tomás ya había apuntado a determinadas causas que pueden modificar la articulación de diptongos y de hiatos. Al referirse a palabras con se- 
2. Conciencia de la independencia de la ortografía respecto al criterio fonético tradicional, hecho que, a lo largo de las obras académicas desde 1952, se expresa mediante fórmulas como «a efectos ortográficos», «para las reglas del acento ortográfico», «prácticamente», "para la práctica de la escritura»...

3. Fijación de los conceptos, primero, y, más tarde, de las expresiones diptongo, triptongo e hiato ortográficos.

\subsection{Primer avance: el diptongo ortográfico ui}

La conciencia de que determinadas combinaciones vocálicas se articulan ya como diptongos, ya como hiatos, se explicita sobre todo en las reflexiones sobre la secuencia /ui/. Julio Casares (1951) advirtió esta variabilidad:

Esta combinación suele aparecer hoy formando diptongo, como en juicio, buitre, cuita, fuiste, etc.; pero otras veces muestra vacilación. Así, mientras en ruido, ruin, suizo, predomina la tendencia al diptongo, se advierte preferencia por el hiato en jesu-ita, altru-ista, casu-ismo, fortu-ito, etc. Y muy especialmente en los infinitivos, participios y formas personales de los verbos en -uir: destru-ir, destru-ido, destru-imos (J. Casares, 1951: §56, Caso V, a: 435).

La propuesta que realiza la RAE en Nuevas normas de prosodia y ortografía (1952) se sitúa por encima de esta variabilidad. Cualquiera que sea su realización fónica (hiato o diptongo), en la práctica ortográfica («p rá c tic a m e n te») se han de tratar siempre como diptongos:

cuencias vocálicas en las que aparecen $i, u$, sostiene que normalmente se realizan como diptongos (aire, gaita, llamáis, aciago, vaciáis...flauta, causa, guapo, cuarto...). Pero apostilla:

En ciertos casos, sin embargo, la tendencia fonética a reducir grupos de vocales a una sola sílaba lucha con influencias etimológicas o analógicas, siendo posible pronunciar una misma palabra con reducción o sin reducción. El lenguaje lento, el acento enfático y la posición final favorecen en dichos casos el hiato. La pronunciación rápida y el tono corriente y familiar dan preferencia a la sinéresis. (T. Navarro Tomás, $1990^{24}:$ 158). 
La combinación ui se considerará prácticamente como diptongo en todos los casos (RAE, 1952, Norma 23.ㄹ: 20.).

En las Nuevas normas de Prosodia y Ortografía, de obligado cumplimiento desde el 1. ${ }^{\circ}$ de enero de 1959, la RAE expresará esta regla con una formulación incluso más explícita («para la práctica de la escritura»):

La combinación ui se considerará, para la práctica de la escritura, como diptongo en todos los casos (Id. Norma 13. ․: 5)

Hemos de fijar la atención a las expresiones práctic a me n te y para la práctica de la escritura de las dos citas anteriores. Con ellas se está estableciendo la autonomía del criterio ortográfico frente al criterio fonético tradicional $y$, a la vez, asistimos a la forja de un nuevo concepto (el de 'diptongo ortográfico') antes de que se fije su denominación en la OLE10.

\subsection{Segundo avance: otros diptongos ortográficos}

La expresión «a efectos ortográficos», que consolida la autonomía de la ortografía sobre la fonética en el tratamiento de los diptongos, se fija en la Ortografía académica de 1969 y en la de 1974:

Debe tenerse en cuenta que, a los efectos ortográficos, para que haya diptongo es preciso que las vocales extremas $i, u$ se junten entre sí o con cualquiera de las de articulación intermedia $e, a, o \ldots{ }^{4}$.

La articulación fónica de las secuencias vocálicas como diptongo o como hiato en español ofrece numerosísimos casos de vacilación. En la mayor parte de las combinaciones (concretamente, cuando la vocal cerrada no es tónica) el hecho de que se realicen como hiatos o como diptongos no es cuestión de sistema, sino 
de norma (cf. §, 4.2) ya que esta variación no se corresponde con cambios de significado: bi.e.nio bie.nio, bi.om.bo biom.bo, di.a.rio $\sim$ dia.rio, em.bri.ón em.brión, a.nu.al a.nual, cru.el $\sim$ cruel...

Esta variabilidad en la segmentación de las combinaciones vocálicas podría tener consecuencias ortográficas. En la pronunciación de algunas palabras como superfluo, continuo, arduo, tenue, radio, perpetuo, ingenuo, asiduo, ubicuo, heroico, odio, fatuo, congruo, ambiguo, exiguo, antiguo, averiguo, atestiguo, еvacuo, fragua, agua, adecua, exangüe, bilingüe, pingüe... las secuencias vocálicas se articulan bien como diptongos, bien como hiatos, según distintas circunstancias, sin que se modifique el significado: su.per.fluo o su.per.flu.o, te.nue o te.nu.e, radio o ra.di.o, per.pe.tuo o per.pe.tu.o, he.roi.co o he.ro.ico... Caso de seguir el criterio de la pronunciación, las articulaciones su.per.flu.o, mons.tru.o. con.ti.nu.a, per. pe.tu.a, te.nu.e, pin.gü.e, ra.di.o, he.ro.i.co... deberían llevar tilde por ser esdrújulas, mientras que las silabaciones opuestas su.per. fluo, mons.truo, con.ti.nua, per.pe.tua, te.nue, pin.güe, ra.dio, he.roi. co... no se acentuarían por ser llanas. Para evitar estas incómodas duplicidades, la ortografía había elegido de forma implícita la opción más sencilla: considerar que las secuencias vocálicas de estas voces forman ortográficamente siempre diptongo, cualquiera sea su pronunciación. Esta opción se hizo explícita en la Ortografía académica de 1974:

Las terminaciones $u o, u a, u e$, cuando ninguna de sus vocales es tónica, se consideran siempre diptongo a efectos ortográficos, cualquiera sea su pronunciación real [Subrayado nuestro]. Se entiende, pues, que son llanas y no deben llevar tilde en la vocal tónica tanto palabras como agua, ambiguo, antiguo, exiguo, fragua, exangüe, bilingüe, que siempre se pronuncian como diptongo, cuanto congrua, ingenuo, superfluo, donde la pronunciación vacila entre el diptongo y el hiato. (OLE74, Cap. III, §36e: 26).

En esta cita no solo aparece la fórmula «se consideran siempre diptongo a efectos ortográficos» sino su referencia a la superación 
de la variabilidad fonética: «cualquiera sea su pronunciación real». La norma se extiende por analogía a palabras que incluyen las secuencias ia, io, ie tras la sílaba tónica: soberbia, Amalia, Arcadia, cinabrio, paladio, estadio, armonio, pandemonio, cuadrivio, trivio, superficie...

\subsection{Tercer avance: la Ortografía de 1999}

La OLE99 hereda la conciencia de la autonomía de la disciplina ortográfica sobre la variabilidad fonética. Repite asimismo las fórmulas que utilizaban las obras previas de la RAE («a efectos ortográficos»), pero tendrá el mérito de definir todos los diptongos según el nuevo criterio y de aplicar su análisis a otras combinaciones más problemáticas, incluidos los monosílabos ortográficos (vid. supra §1.1).

\subsection{Las denominaciones diptongo, triptongo e hiato ortográ-} ficos (OLE10)

La OLE10 destina el apartado $§ 2$ del CAPÍtULO II al acento prosódico. Aquí se definen, como es natural, las nociones de diptongo, triptongo e hiato en su relación con la fonética ${ }^{5}$. El apartado siguiente (§3) del mismo capítulo estudia el acento gráfico o tilde. Es en este espacio donde se proponen los innovadores conceptos y denominaciones de diptongo, triptongo e hiato ortográficos. En su caracterización, no solo se prescinde de criterios fonéticos, sino que se afirma expresamente que en ortografía determinadas secuencias vocálicas forman diptongo, triptongo o hiato sin tener en cuenta su pronunciación:

- Diptongos ortográficos. «Los diptongos son secuencias de dos vocales que forman parte de una misma sílaba. Con independencia de cómo se articulen realmente en cada caso, se consideran siempre diptongos a efectos ortográficos las siguientes combinaciones vocálicas...» (OLE10: 235).

5 «Los diptongos son secuencias de dos vocales que se pronuncian en la misma sílaba» (OLE10: 197). «Los triptongos son secuencias de tres vocales pronunciadas dentro de la misma sílaba» (OLE10: 198). «Los hiatos son secuencias de dos vocales que se pronuncian en sílabas distintas» (OLE10: 198). 
- Triptongos ortográficos. «Los triptongos son secuencias de tres vocales que forman parte de una misma sílaba. Con independencia de cómo se articulen realmente en cada caso, se consideran siempre triptongos a efectos ortográficos las secuencias formadas...» (OLE10: 237)

- Hiatos ortográficos. «Cuando dos vocales seguidas dentro de una palabra pertenecen a sílabas distintas, constituyen un hiato [...]. Con independencia de cómo se articulen realmente en cada caso concreto, se consideran siempre hiatos a efectos de acentuación gráfica las combinaciones vocálicas siguientes...» (OLE10: 238).

\subsection{Resumen de la posición normativa}

Los cambios teóricos afectaron a la posición normativa de las academias respecto a la acentuación gráfica de determinadas palabras como guion, Sion, truhan, Ruan, crie, fie, guie, lie, crio, fio, guio, lio, rio, criais, fiais, guiais, liais, riais, crieis, fieis, guieis, lieis... En esta evolución se distinguen tres etapas:

1. a Antes de 1999. Se consideraba que eran palabras bisílabas agudas. Llevaban obligatoriamente tilde: guión, truhán, Sión, lió, fié, pié (de piar)...

2. - Desde 1999 a 2010. Se considera que son diptongos ortográficos (por lo tanto, monosílabos) ${ }^{6}$. No deberían llevar tilde, pero se permite la doble posibilidad de acentuarlos gráficamente o no ${ }^{7}$ : guion guión, Sion Sión, truhan truhán, fio fió, fie fié, fiais fiáis, fieis $\sim$ fiéis, lio $\sim$ lió, lie $\sim$ lié, liais $\sim$ liáis, lieis $\sim$ liéis, etc.

6 «A efectos ortográficos, son monosílabos las palabras en las que por aplicación de las reglas expuestas en los párrafos anteriores, se considera que no existe hiato - aunque la pronunciación así parezca indicarlo-, sino diptongo o triptongo. Ejemplos: fie (pretérito perfecto simple del verbo fiar), hui (pretérito perfecto simple del verbo huir), riais (presente de subjuntivo del verbo reír), guion, Sion. etc.» (OLE99: 46).

7 La OLE99, en contradicción con el principio que acaba de formular, deja el hecho de poner tilde o no al criterio subjetivo de los hablantes: «En este caso es admisible el acento gráfico, impuesto por las reglas de ortografía anteriores a estas, si quien escribe percibe nítidamente el hiato y, en consecuencia, considera bisílabas palabras como las mencionadas: fié, huí, riáis, guión, Sión, etc.». (OLE99: 46). 
3.․ Desde 2010. Se fijan definitivamente los conceptos de diptongo, triptongo e hiato ortográficos. Se considera también que estas voces son monosílabas. En congruencia con la teoría, se decide que no deben acentuarse: guion, Sion, truhan, fio, fie, fiais, fieis, lio, lie, liais, lieis, guio, guiais, guieis, etc. ${ }^{8}$.

Esta sucesión de cambios de norma en un período tan corto ha resultado difícil de entender y asimilar, por lo que no han sido pocas las personas que han manifestado su perplejidad, tanto con la adopción del criterio como con la forma, a veces incongruente, de aplicarlo.

\section{Críticas}

Las sucesivas decisiones adoptadas por la RAE en la OLE99 y la OLE10 fueron recibidas, como es esperable en toda modificación ortográfica, con división de opiniones. Desde el ámbito de la didáctica de la ortografía fueron asumidas no solo con respeto, sino con unánime aplauso. La sencilla forma de determinar

8 La Academia ya se había adelantado parcialmente a esta conclusión al decidir que las secuencias $u i$, cualquiera fuera su articulación, debían considerarse "prácticamente» diptongos (RAE, 1952, norma 23. a , pág. 20). Esta resolución afectaba a secuencias que daban como resultado monosílabos ortográficos: «Las formas pretéritas de indicativo (primera persona singular y segunda persona plural), ya tratados anteriormente de los verbos monosílabos terminados en -uir: flui, fluis; frui, fruis; grui, gruis; hui, huis; lui, luis; mui, muis; no llevan tilde en la escritura porque la combinación vocálica $u i$ (cerrada + cerrada) es siempre un diptongo indisoluble en la lengua española y son por eso formas invariablemente monosílabas» (J.G. Medina Sánchez 2007: 52). Se extraña este autor de que la misma Academia no haya aplicado la norma a estos monosílabos: «Sorprende ver en el Esbozo de la nueva gramática de la lengua española (pr. 1.8.3, E, 1ํ) las formas verbales monosilábicas *huí, “huís con una tilde innecesaria» (ibid.). Esta misma observación es realizada atinadamente por L. Gómez Torrego: «En cuanto a las palabras hui, huis, frui, fruis, flui, fluis, hay que decir que se venían acentuando, pero esa tilde contradecía otra norma que se había dado para la secuencia vocálica - $u$ i- en las normas de 1959, y que sigue en vigor, consistente en que esta secuencia, a los efectos de acentuación, debía considerarse diptongo, por lo que al ser monosílabo no deberían haberse tildado nunca» (L. Gómez Torrego, 2013: 70). El autor reclama la existencia de un diptongo ortográfico que hace monosílabas las palabras huí, fruí..., diptongo de la misma naturaleza que los diptongos ortográficos que critica (Id.: 69) (vid. más adelante $\S 3$ ). 
cuándo hay diptongo (o triptongo) y cuándo existe hiato facilita enormemente la enseñanza de la ortografía en este punto. Sin embargo, no faltaron manifestaciones críticas, incluso de voces autorizadas.

La oposición más argumentada frente a las nociones de diptongo ortográfico y de hiato ortográfico es la de L. Gómez Torrego (2013: 68 y ss.). La primera parte de su exposición resume las causas que motivaron el cambio de postura de la RAE respecto al tratamiento ortográfico tradicional que la institución hacía de diptongos, triptongos y de hiatos:

Otro de los cambios que ha suscitado polémica mediática es la supresión de la tilde en las palabras que, como guion, la llevaban hasta hace poco tiempo. Este tipo de palabras se pronuncia en casi todo el territorio peninsular de España y en gran parte de América como bisílabas, es decir, con hiato, pero con la vocal abierta como elemento tónico: guion [gi-ón], truhan [tru-án], fie [fi-é]... Sin embargo, en otras zonas de América (México, Centroamérica) se pronuncian normalmente como diptongos: guion [gjón], truhan [trwán], fie [fjé]... Como las normas ortográficas se dictaban generalmente desde la $R A E$, y en España lo normal era y es pronunciar estas palabras como bisílabas, se prescribió la tilde en este tipo de palabras, ya que eran bisílabas agudas acabadas en vocal, en $-n$ o en $-s$. Ahora bien, desde la óptica panhispánica, al no haber coincidencia en la pronunciación de estas palabras en la lengua esmerada, se ha optado por eliminar la tilde y considerar que en ellas, a los efectos de la acentuación (se pronuncien como se pronuncien) hay siempre diptongo; es el llamado por algunos diptongo gráfico: unión de una vocal cerrada seguida de una abierta tónica, de una vocal abierta tónica seguida de una cerrada y de dos vocales cerradas (L. Gómez Torrego, 2013: 68).

Antes de examinar la crítica propiamente dicha, conviene realizar alguna puntualización:

a) Como se ha mostrado más arriba ( $\$ 2.2$ y $\S 2.3)$, la consideración de secuencias vocálicas como diptongos a efectos 
ortográficos (es decir, con independencia de su pronunciación tautosilábica o heterosilábica), es anterior a la OLE99. La primera decisión de la RAE en este sentido tiene lugar en las Nuevas normas de prosodia y ortografía (1952) a propósito de las secuencias -ui- (jesuita, obstruir, casuismo... $)^{9}$ y se ha mantenido desde entonces de forma invariable. La segunda intervención tiene lugar en la OLE69 y, más explícitamente, en la OLE74 a propósito de las palabras que incluyen en su última sílaba las secuencias vocálicas uo, ua, ue y ninguna es tónica (ambiguo, tenue, superflua...). Este acuerdo también se ha mantenido sin modificar hasta el presente.

b) La diferencia diatópica en la forma como se articulan guion, truhan, fie... en México y Centroamérica, por un lado, y en España y resto del mundo hispánico, por el otro, no es la única causa en la que la RAE fundamenta su cambio de criterio. La OLE99 enuncia otras razones: «su lugar en la secuencia hablada, el mayor o menor esmero en la pronunciación, el origen geográfico o social de los hablantes, etc.»(OLE99: 43). En cualquier pronunciación rápida, también en España, se articularían como diptongos o triptongos las secuencias vocálicas de las palabras subrayadas: ¡No os fieis de él!, Le crio una abuela, ¡Ya la lie!! Si el criterio ortográfico decisivo para discriminar entre hiato y diptongo fuera la pronunciación (es decir, la articulación fonética real demostrable por análisis), se debería

9 El mismo L. Gómez Torrego cita más abajo, como ejemplo de variación articulatoria posible, los casos de jesuita, gratuito y viuda:

De la misma manera, hay palabras en las que unos pronuncian diptongo, como jesuita, gratuito, viuda ([xeswíta], [gratwíto], [bjúda]), y otros, hiatos ([xesuíta], [gratuíto], [biúda]). (L. Gómez Torrego, 2013: 69).

No advierte, sin embargo, que la RAE en 1952 cuando toma el acuerdo de escribir sin tilde las secuencias - $u i$ - cualquiera fuese su pronunciación, supera el criterio fonético y está alumbrando un nuevo concepto: el de diptongo ortográfico. Esta decisión cerró un problema que ocupó varios decenios de polémica y de cambios de criterio. 
colocar tilde cuando estas secuencias se realicen como hiatos y no ponerla cuando se emitan como diptongos. ¡El caos!

c) Este nuevo concepto no solo es «llamado por algunos» diptongo ortográfico ${ }^{10}$, sino que fue acuñado y propuesto por la misma obra (cf. OLE10: 235).

Más importantes que estas reflexiones iniciales son las críticas y la solución que ofrece Gómez Torrego para este problema:

El concepto de diptongo gráfico sorprende, pues un diptongo se define en el DRAE (y en las obras de carácter fonético y fonológico) como «secuencia de dos vocales diferentes que se PRONUNCIAN (la mayúscula es nuestra) en una sola sílaba». Por lo tanto, el diptongo es un concepto lingüístico que pertenece exclusivamente al ámbito fónico, no al gráfico. De la misma manera, el concepto de hiato gráfico también parece gratuito e inventado para poder explicar el cambio en la acentuación de las palabras que aquí comentamos. Otra cosa es que haya palabras que en unas zonas se pronuncien como diptongos y que en otras se pronuncien como hiatos y viceversa (L. Gómez Torrego, 2013: 69).

1) Tiene razón L. Gómez Torrego al afirmar que el DLE (también la OLE99) define las nociones de diptongo y de hiato desde el punto de vista de la pronunciación, es decir, desde un criterio fonético. Sin embargo, como se ha mostrado más arriba (§ 2.5), la OLE10 diferencia el ámbito fonético del ámbito ortográfico: define las nociones de diptongo, triptongo o hiato con criterios fónicos en el $\S 2$ (EL ACENTO PROSÓDICO), pero con criterios ortográficos en el § 3 (EL ACENTO GRÁfico o TILDE).

2) Aun en el supuesto de que las nociones de diptongo, triptongo e hiato fueran de índole fónica, no serían, en modo 
alguno, conceptos simples de definir y fáciles de determinar en la práctica. Varían según se las trate con criterio fonético, morfológico, dialectal, métrico, ortofónico, fonológico u ortográfico. Sin entrar por ahora en detalles, obsérvese que en métrica se consideran diptongos casos que nunca lo serían si se sigue el análisis prosódico tradicional (por ejemplo, las realizaciones de la sinalefa y de la sinéresis). En el verso forman diptongos incluso secuencias de vocales abiertas («En tanto que de aurora...»). Hoy no cabe el subterfugio de que se trata de figuras cuyo uso se restringe al ámbito de la métrica. La pronunciación normal de Fuenteovejuna no difiere de la sinéresis del verso de Lope (Fuentęvejuna, señor). Más aún, como mostraron A. Bello y T. Navarro Tomás, en contexto de sinalefa, son posibles sílabas formadas por cuatro e incluso por cinco vocales («Envidio a Eusebio» ${ }^{11}$ ).

3) No es asumible la idea de que «el diptongo es un concepto lingüístico que pertenece exclusivamente al ámbito fónico, no al gráfico», $\mathrm{y}$, mucho menos, la dura afirmación de que el diptongo ortográfico es un concepto «gratuito e inventado para poder explicar el cambio en la acentuación de las palabras que aquí comentamos». Todo lo contrario: la gran innovación científica y didáctica de las dos últimas versiones de la OLE99 y de la OLE10 en este ámbito (inspirada en decisiones anteriores) reside en lograr definir de forma inmanente (solo con criterios ortográficos) las nociones de diptongo y de hiato. Es una innovación científica porque se formulan unas reglas que permiten determinar en cada secuencia de vocales si se trata de un diptongo o de un hiato con independencia de la realización fonética. Es una innovación con repercusiones didácticas porque, a la hora de decidir si una secuencia de vocales forma diptongo o

11 T. Navarro Tomás, 1990: 72. A. Bello recoge un ejemplo de cuatro vocales: «sabia Europa (iaeu)» (A. Bello, 1835: 55). 
hiato, los alumnos (y, en general, todos los usuarios de la lengua escrita) ya no necesitan acudir al criterio de la pronunciación, tan inseguro y subjetivo. Hoy es tan evidente sostener que las nociones de diptongo y de hiato tienen una dimensión fonética y otra gráfica (cada una definida según sus criterios) como afirmar que los conceptos de vocal y de consonante poseen esas mismas dimensiones. Existen tanto sonidos como letras vocálicos y consonánticos, relacionados pero autónomos ${ }^{12}$.

\section{Nociones metodológicas}

Como se ha afirmado más arriba, los conceptos de diptongo y de hiato no son simples. La decisión que se adopte para caracterizarlos está mediatizada por el ámbito en el que se analice (fonético, morfológico, métrico, fonológico y ortográfico). Antes es necesario recordar algunas distinciones clásicas que serán indispensables para situar bien algunos puntos de la exposición.

\subsection{Fonética, fonología y escritura}

La aparición de la fonología, al aplicar el principio de distintividad, consiguió descripciones más explicativas y más simples que la fonética. Diferenció lo funcional de lo material, lo distintivo de lo no distintivo, lo relevante de lo que no lo es.

La fonología puso de relieve que las escrituras alfabéticas son esencialmente fonológicas. Las letras o grafemas tienen como objetivo esencial representar los fonemas, no los sonidos. La escritura no utiliza letras diferentes para distinguir distintas variantes fónicas de un mismo fonema. La relación entre fonología y ortografía servirá también para fundamentar las nociones de diptongo ortográfico e hiato ortográficos.

12 «Debe notarse que los términos vocal y consonante significan no solamente las dos especies de sonidos elementales de que se componen todas las palabras, sino las letras o caracteres que los representan en la escritura» (A. Bello, 1835: 2). 


\subsection{Sistema, norma, habla}

De indudable valor en esta argumentación ortográfica será la brillante propuesta por E. Coseriu de distinguir las nociones sistema/norma/habla:

...podemos decir que el sistema es un conjunto de oposiciones funcionales; la norma es la realización colectiva del sistema, que contiene el sistema mismo y, además, los elementos funcionamiento "no pertinentes" pero normales en el hablar de una comunidad; el hablar (o, si se quiere, habla) es la realización individualmente concreta de la norma, que contiene la norma misma y, además, la originalidad expresiva de los individuos hablantes (E. Coseriu, 1967: 59).

Aplicado al problema de los diptongos, el hecho de que palabras como guion, truhan o fie se articulen generalmente como bisílabas en España y como monosílabas en México y Centroamérica es un hecho de norma. Sin embargo, tal diferencia no afecta al sistema, ya que no es un fenómeno distintivo: la diferencia fónica entre la articulación con hiato ([gi.ón], ([tru.án]) y con diptongo ([gjón], ([trwán]) no modifica el significado. La ortografía es fonológica, se atiene a hechos de sistema. No debe distinguir lo que no distingue la lengua.

\subsection{La norma prescriptiva}

El término norma posee un segundo sentido, alejado de la acepción forjada por Coseriu ${ }^{13}$. Esta acepción está anclada en la dimensión prescriptiva ('normativa') de la gramática, que propone modelos de corrección, de pureza en el uso de la lengua (cri-

13 El mismo Coseriu puso cuidado en advertir esta diferencia conceptual: «Aclaramos además que no se trata de la norma en el sentido corriente, establecido o impuesta según criterios de corrección y de valoración subjetiva de lo expresado, sino de la norma objetivamente comprobable en una lengua, la norma que seguimos necesariamente por ser miembros de una comunidad lingüística y no aquella según la cual se reconoce que "hablamos bien" o de manera ejemplar en la misma comunidad» (E. Coseriu,1967: 53). 
terios prosódicos). La prosodia, una sección de la ortología ${ }^{14}$, era definida como «la parte de la Gramática que enseña la recta pronunciación de las letras, las sílabas y las palabras» (RAE, 1895: 321). La prosodia tradicional, de carácter normativo, no basada en criterios fonológicos, ha condicionado con sus análisis y propuestas la concepción ortográfica de diptongos e hiatos durante mucho tiempo. Y, lo que es peor, sigue envenenando muchas de las reflexiones y discusiones actuales sobre el tema.

\section{Fonología de los diptongos y de los hiatos}

\subsection{Función distintiva}

En los apartados previos se ha mostrado que muchas secuencias vocálicas consideradas tradicionalmente hiatos se articulaban en determinados contextos o en determinadas zonas geográficas como diptongos. Se daba también el caso contrario. Por ello, es necesario acotar con mayor precisión los límites y las causas de este fenómeno:

a) ¿Es siempre posible esta alternancia diptongo-hiato? ¿Siempre que tenemos un diptongo lo podemos articular como hiato? ¿Cualquier hiato permite ser realizado como diptongo?

b) ¿Cuáles son las razones en las que se fundamenta la posibilidad o imposibilidad de estas alternancias en la pronunciación?

La respuesta a la primera pregunta es negativa. Los hiatos formados por una vocal débil tónica suelen ser estables ${ }^{15}$ : ganzúa ( ${ }^{*}$ ganzuá), dúo (*duo), sonríe (* sonrié), etc. Las demás combinacio-

14 «El objeto de la Ortolojía es la recta pronunciación de las palabras. La Ortolojía tiene tres partes: la primera trata de los sonidos elementales de las palabras; la segunda de sus acentos; la tercera de sus cantidades o tiempos. A las dos últimas suele darse ordinariamente el nombre de Prosodia» (A. Bello: 1835: 1).

15 Se exceptúan algunas deshiatizaciones que afectan a casos reducidos y casos de pronunciaciones del tipo ahí (por ahî), pais (por país). 
nes vocálicas poseen menor consistencia: te.nue te.nu.e, fa.tuo fa.tu.o, fau.no $\sim$ fa.u.no, a.grio $\sim$ a.gri.o, fie.ra $\sim$ fi.e.ra ${ }^{16}$. La razón que sustenta la respuesta a ambas preguntas es de índole fonológica:

1) La ubicación del acento en la vocal cerrada de una secuencia vocálica opone la palabra a la que pertenece a voces isofonemáticas con acento en la vocal abierta: actúe/actué, fluctúo/fluctuó, varíe/varié, río/rio... teníaltenia, sabíalsabia, paría/paria, etc. Es decir, en el ámbito de una combinación de vocales cerrada-abierta o abierta-cerrada, la posición del acento posee relevancia fonológica.

2) Por el contrario, cuando el acento no recae sobre la vocal cerrada, la realización de la secuencia de vocales como hiato o como diptongo no tiene repercusiones en el contenido: au.la a.u.la, sua.ve su.a.ve, cruel cru.el, feu.do fe.u.do, rue.da ru.e.da, cuo.ta cu.o.ta, frai.le fra.i.le, ra.dio $\sim$ ra.di.o, vi.drio $\sim$ vi.dri.o, na.die $\sim$ na.di.e, con.ti.nuo $\sim$ con. ti.nu.o, mons.truo $\sim$ mons.tru.o, te.nue $\sim$ te.nu.e, rau.do $\sim$ ra.u. do, etc. Es posible (incluso frecuente) que en determinadas palabras una de las variantes se realice mayoritariamente como diptongo o como hiato. Sin embargo, este hecho no es relevante. Lo que importa es comprobar que, si el acento recae sobre la vocal abierta, la sustitución de hiato por diptongo (o viceversa) en ningún caso posee valor distintivo. No produce alteraciones del significado. Por consiguiente, en estas circunstancias, hiato y diptongo son variantes de una misma forma fonológica. O lo que es lo mismo, la realización de una secuencia de vocales como hiato o como diptongo no es relevante desde el punto de vista fonemático. Lo único que es distintivo es la posición del acento en una o en otra vocal.

16 “En muchos casos, la combinación de un segmento vocálico con el rasgo [+alto] y otro con el rasgo [-alto] está sometida a vacilaciones en la pronunciación. Así, por ejemplo, anual, biombo, crueldad o diana pueden realizarse como hiato o como diptongo en función de diversos factores de carácter espacial, estilístico o social. En ocasiones, la etimología o la analogía influyen en la solución fonética." (NGLEFF11: 337). 


\subsection{Relevancia fonológica de la posición acentual y escritura}

5.2.1 Análisis de las distribuciones. Los siguientes cuadros comparativos recogen los dos tipos de combinaciones presentadas en el apartado anterior:

- Voces con secuencias vocal cerrada acentuada + vocal abierta átona (I).

- Voces con secuencias vocal cerrada átona + vocal abierta tónica (II).

\begin{tabular}{|c|c|c|c|c|}
\hline \multicolumn{2}{|c|}{ I } & \multicolumn{3}{|c|}{ II } \\
\hline ESCRITURA & SILABACIÓN & SILABACIO & & ESCRITURA \\
\hline & & $\mathrm{A}$ & $\mathrm{B}$ & \\
\hline confio & [konfí.o] & [konfi.ó] & [konfjó] & confió \\
\hline desafío & [desafí.o] & [desafi.ó] & [desafjó] & desafió \\
\hline envío & [embí.o] & [embi.ó] & [embjó] & envió \\
\hline enfrío & [enfrí.o] & [enfri.ó] & [enfrjó] & enfrió \\
\hline deslío & [deslí.o] & [desli.ó] & [desljó] & deslió \\
\hline espie & [espí.e] & [espi.é] & [espjé] & espié \\
\hline enfrié & [enfrí.e] & [enfri.é] & [enfrjé] & enfrié \\
\hline acentúe & [aӨentú.e] & [aӨentu.é] & [äentwé] & acentué \\
\hline conceptúo & [konӨeptú.o] & [konӨeptu.ó] & [konӨeptwó] & conceptuó \\
\hline actúo & [aktú.o] & [aktu.ó] & [aktwó] & actuó \\
\hline actúe & [aktú.e] & [aktu.é] & [aktwé] & actué \\
\hline atenúe & [atenú.e] & [atenu.é] & [atenwé] & atenué \\
\hline fluctúe & [fluktú.e] & [fluktu.é] & [fluktwé] & fluctué \\
\hline
\end{tabular}

De la observación de este cuadro se obtienen las siguientes conclusiones:

1. Las pronunciaciones de la columna (I) se oponen fonológicamente a las articulaciones de la columna (II). Se produce un cambio en la posición del acento dentro de la secuencia vocálica que tiene repercusiones en el significado $^{17}$. La transcripción fonológica expresa la oposición: / konfio/-/konfiól, /desafio/-/desafió/.

17 Obsérvese que lo importante es el cambio de posición del acento. El hecho de que cuando la intensidad cae sobre la vocal cerrada se produzca hiato es una consecuencia. «El sistema de reglas de acentuación no tiene como función indicar si una secuencia vocálica se articula en una sola sílaba o en sílabas distintas». (OLE10: 218). 
2. Las pronunciaciones correspondientes a las columnas (A) y (B) no se oponen fonológicamente. Es decir, cuando el acento no recae en la vocal cerrada, la realización hiato $\sim$ diptongo de dicha secuencia no es distintiva. La transcripción fonológica de [kon.fi.ó] y de [kon.fjó] es la misma: /konfió/.

3. La escritura refleja los valores fonológicos, no las realizaciones fonéticas: distingue la posición del acento, pero no aporta información sobre el carácter de hiato o de diptongo de las secuencias vocálicas. Por lo tanto, la escritura de [kon.fi.ó] y de [kon.fjó] es la misma: confió.

4. Al tratarse de voces polisilábicas agudas terminadas en vocal, las secuencias del grupo (II) se acentúan ortográficamente (confió, desafió, envió, actué, fluctué...).

La irrelevancia fonológica de las realizaciones del grupo (II) se mantiene incluso cuando la posibilidad del grupo (I) es defectiva, es decir, cuando no existen voces opuestas con acento en la vocal cerrada:

\begin{tabular}{|c|c|c|c|c|}
\hline \multicolumn{2}{|r|}{ I } & \multicolumn{3}{|c|}{ II } \\
\hline \multirow{2}{*}{ ESCRITURA } & \multirow[t]{2}{*}{ PRONUNCIACIÓN } & \multicolumn{2}{|c|}{ PRONUNCIACIONES } & \multirow[t]{2}{*}{ ESCRITURA } \\
\hline & & A & B & \\
\hline$\varnothing$ & $\varnothing$ & [ti.ára] & [tjára] & tiara \\
\hline$\varnothing$ & $\varnothing$ & [pi.áno] & [pjáno] & piano \\
\hline$\varnothing$ & $\varnothing$ & [ri.áda] & [rjáda] & riada \\
\hline$\varnothing$ & $\varnothing$ & [bi.áxe] & [bjáxe] & viaje \\
\hline$\varnothing$ & $\varnothing$ & [fi.ánza] & [fjánza] & fianza \\
\hline$\varnothing$ & $\varnothing$ & [kri.ár] & [krjár] & criar \\
\hline$\varnothing$ & $\varnothing$ & [ $\theta$ i.égo] & [Ojégo] & ciego \\
\hline$\varnothing$ & $\varnothing$ & [ $\theta$ i.élo] & [ $\theta$ jélo] & cielo \\
\hline$\varnothing$ & $\varnothing$ & [di.éta] & [djéta] & dieta \\
\hline$\varnothing$ & $\varnothing$ & 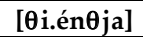 & [ $\theta$ jén $\theta$ ja] & ciencia \\
\hline$\varnothing$ & $\varnothing$ & [bi.énjo] & [bjénjo] & bienio \\
\hline$\varnothing$ & $\varnothing$ & [su.élo] & [swélo] & suelo \\
\hline$\varnothing$ & $\varnothing$ & [su.éño] & [swéño] & sueño \\
\hline$\varnothing$ & $\varnothing$ & [su.érte] & [swérte] & suerte \\
\hline$\varnothing$ & $\varnothing$ & [fu.égo] & [fwégo] & fuego \\
\hline$\varnothing$ & $\varnothing$ & [bu.éno] & [bwéno] & bueno \\
\hline$\varnothing$ & $\varnothing$ & 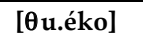 & [ $\theta$ wéko] & zueco \\
\hline
\end{tabular}




\subsubsection{Secuencias de escaso cuerpo fónico}

Este mismo comportamiento se observa cuando las voces poseen un cuerpo fónico más reducido. En ocasiones, existe oposición entre voces homófonas que acentúan la vocal cerrada (I) o vocal abierta (II): crío/crio...

\begin{tabular}{|c|c|c|c|c|}
\hline \multicolumn{2}{|r|}{ I } & \multicolumn{3}{|c|}{ II } \\
\hline ESCRITURA & PRONUNCIACIÓN & PRONUNC & & ESCRITURA \\
\hline & & A & B & \\
\hline crío & [krí.o] & [kri.ó] & [krjó] & crio \\
\hline frío & [frí.o] & [fri.ó] & [frjó] & frio \\
\hline guío & [gí.o] & [gi.ó] & [gjó] & guio \\
\hline lío & [lí.o] & [li.ó] & [ljó] & lio \\
\hline río & [rí.o] & [ri.ó] & [rjó] & rio \\
\hline pío & [pí.o] & [pi.ó] & [pjó] & pio \\
\hline fie & [fí.e] & [fi.é] & [fjé] & fie \\
\hline lie & [lí.e] & [li.é] & [ljé] & lie \\
\hline píe & [pí.e] & [pi.é] & [pjé] & pie \\
\hline guíe & [gí.e] & [gi.é] & [gjé] & guie \\
\hline
\end{tabular}

Las conclusiones que se obtienen del análisis de estos ejemplos no son diferentes a las obtenidas con las series anteriores:

1 Las pronunciaciones de la columna (I) se oponen a las articulaciones de la columna (II). Se produce un cambio en la posición del acento dentro de la secuencia de vocales asociado a una modificación de sentido (río/rio). La representación fonológica refleja esta oposición: /krío/-/krió/, / fíe/-/fié/.

2 La distinta silabación de las columnas (A) y (B) no es pertinente fonológicamente. Es decir, cuando el acento recae en la vocal abierta, la realización hiato $\sim$ diptongo no es relevante. La transcripción fonológica de [kri.ó] y de [krjó] es la misma: /krió/.

3 La escritura refleja los valores fonológicos, no las variaciones fonéticas: distingue la posición del acento (crío/crió), pero no aporta información sobre el carácter de hiato o de diptongo de las secuencias vocálicas en que el acento destaca la vocal fuerte: crio, frio, guie... 
En estas secuencias fónicas breves, también hallamos casos de situación defectiva en la columna (I), es decir, de palabras con acento en la vocal cerrada. Muchos de ellos se corresponden con secuencias de tres vocales. Su análisis es el mismo y la solución ortográfica (son triptongos ortográficos), idéntica:

\begin{tabular}{|l|l|ll|l|}
\hline \multicolumn{2}{|c|}{ I } & \multicolumn{3}{c|}{ II } \\
\hline ESCRITURA & PRONUNCIACIÓN & \multicolumn{1}{|c|}{ PRONUNCIACIONES } & ESCRITURA \\
\hline & & A & B & \\
\hline$\varnothing$ & $\varnothing$ & [kri.éis] & [krjéis] & crieis \\
\hline$\varnothing$ & $\varnothing$ & [kri.áis] & [krjáis] & criais \\
\hline$\varnothing$ & $\varnothing$ & [fri.éis] & [frjéis] & frieis \\
\hline$\varnothing$ & $\varnothing$ & [fri.áis] & [frjáis] & friais \\
\hline$\varnothing$ & $\varnothing$ & [gi.éis] & [gjéis] & guieis \\
\hline$\varnothing$ & $\varnothing$ & [gi.áis] & [gjáis] & guiais \\
\hline$\varnothing$ & $\varnothing$ & [li.éis] & [ljéis] & lieis \\
\hline$\varnothing$ & $\varnothing$ & [li.áis] & [ljáis] & liais \\
\hline$\varnothing$ & $\varnothing$ & [ri.áis] & [rjáis] & riais \\
\hline$\varnothing$ & $\varnothing$ & [pi.éis] & [pjéis] & pieis \\
\hline$\varnothing$ & $\varnothing$ & [pi.áis] & [pjáis] & piais \\
\hline$\varnothing$ & $\varnothing$ & [fi.éis] & [fjéis] & fieis \\
\hline$\varnothing$ & $\varnothing$ & [fi.áis] & [fjáis] & fiais \\
\hline
\end{tabular}

\subsubsection{Palabras de doble forma}

Los casos estudiados en los apartados anteriores se diferencian sustancialmente de aquellos del tipo amoníaco/amoniaco. Son numerosos tipos y variadas las formas como han penetrado en la lengua ${ }^{18}$ :

- Período-periodo, gladíolo-gladiolo, díodo-diodo, bronquíolo-bronquiolo, foliolo-foliolo, pecíolo-peciolo...

- Afrodisíaco-afrodisiaco, amoníaco-amoniaco, austríaco-austriaco, cardíaco-cardiaco, celíaco-celiaco, maníaco-maniaco, olimpíaco-olimpiaco, paradisíaco-paradisiaco, policíaco-policiaco, siríaco-siriaco, zodíaco-zodiaco, ilíaco-iliaco...

- Ilíada-Iliada.

18 La OLE10 dedica a su variedad y a las formas de entrada en la lengua de estos dobletes el apartado § 2.3.3 (cf. págs. 207-212). 
- Nigromancía-nigromancia, quiromancía-quiromancia, disentería-disentería, antinomía-antinomia, hemiplejía-hemiplejia...paraplejía-paraplejia, artroscopía-artroscopia, microscopía-microscopia...

En estos casos sigue siendo válido el principio anterior: existe una diferencia pertinente entre las secuencias con la vocal débil acentuada (amoníaco) y aquellas que llevan el acento en la tónica $(\text { amoniaco })^{19}$. Por eso, aunque no cambie el significado, constituyen dos entradas lexicográficas distintas. La transcripción fonológica es diferente (/a.mo.ní.a.ko/ frente a /a.mo.niá.ko/) y la escritura también (amoníaco/amoniaco):

\begin{tabular}{|c|c|c|c|c|}
\hline \multicolumn{2}{|r|}{ I } & \multicolumn{3}{|c|}{ II } \\
\hline ESCRITURA & PRONUNCIACIÓN & PRONUNCIAC & & ESCRITURA \\
\hline & & A & $\mathrm{B}$ & \\
\hline & [í.a] & [i.á] & [já] & \\
\hline amoníaco & [amoní.ako] & [amoni.áko] & [amonjáko] & amoniaco \\
\hline demoníaco & [demoní.ako] & [demoni.áko] & [demonjáko] & demoniaco \\
\hline elegíaco & [elegí.ako] & [elegi.áko] & [elegjáko] & elegiaco \\
\hline maníaco & [maní.ako] & [mani.áko] & [manjáko] & maniaco \\
\hline quiromancía & [kiroman $\theta i ́ . a]$ & [kiroman $\theta$ i.a] & [kiroman $\theta$ ja] & quiromancia \\
\hline gladíolo & [gladí.olo] & [gladi.ólo] & [gladjólo] & gladiolo \\
\hline díodo & [dí.odo] & [di.ódo] & [djódo] & diodo \\
\hline ilíaco & [ilí.ako] & [ili.áko] & [iljáko] & iliaco \\
\hline período & [perí.odo] & [peri.ódo] & [perjódo] & periodo \\
\hline estadio & [estadí.o] & [estádi.o] & [estádj.o] & estadio \\
\hline acedía & [aঐédí.a] & [aӨédi.a] & [aӨédia] & acedia \\
\hline
\end{tabular}

19 «La doble grafía - con tilde o sin ella - que admitía para estas palabras la Ortografía de 1999 (crie o crié, guion o guión, Ruan o Ruán, etc.) no es asimilable a la que presentan las voces con doble acentuación prosódica (v. § 2.3.3). En los casos de doble acentuación prosódica, la duplicación de grafías está plenamente justificada porque responde a la posibilidad de que el acento recaiga en dos vocales distintas; así, en la forma esdrújula alvéolo [al.bé.o.lo] es tónica la e, mientras que en la variante llana alveolo [al.be.ó.lo] es tónica la primera o» (OLE10: 236). 


\section{La frágil influencia de la frontera morfológica}

\subsection{En la conjugación}

En la realización bisilábica de algunas voces (sobre todo verbales) que incluyen estas secuencias vocálicas puede intervenir la influencia analógica de otras formas de la misma raíz. Así, por ejemplo, la frontera que hallamos en los presentes [krí.o, gí.o, lí.o, fí.o... krí.e, gí.e, pí.e, fí.e] parecería condicionar la realización como hiato de formas en las que el acento recae sobre la vocal fuerte: [kri.ó, kri.áis, gi.ó, gi.áis, li.ó, li.áis...]. Por el contrario, el diptongo que se observa en la primera persona de ra.bio, li.dio, men.guo... influye en la realización tautosilábica de ra.bié, li.dié, men.güé, ra.bia.ron, li. dia.ron, men.gua.ron... El problema ya había sido planteado con su habitual intuición por A. Bello y también por T. Navarro Tomás:

B. La analojía de la conjugacion determina la cantidad lejítima de las formas verbales. Por ejemplo, fio y cambio son disílabos. Luego fiamos y cambiamos son trisílabos, porque la primera persona del plural del presente o pretérito perfecto de indicativo añade una sílaba a la primera de singular del presente; amo, amamos. De lo cual se sigue que la combinación iá forma naturalmente dos sílabas en fiamos, y diptongo en cambiamos. Por razones análogas las combinaciones ié, ió, son disílabas en fié, fió y diptongos en cambié, limpió; y las combinaciones uá, ué, disílabas en valuamos, valuemos, forman diptongos en fraguamos, fragüemos (A. Bello, 1835: 46-47.).

La analogía favorece el hiato, especialmente en las formas verbales, cuando dentro del mismo verbo de que se trata hay casos en que las vocales $i, u$, llevan el acento fuerte: fiar, fianza (fían); guiaba (guía); liamos (lías); piando (pían); criado, crianza (crían); acentuar (acentúo), actuamos (actúan), etc. Ocurre también entre los nombres: diario, diana, diurno, dieta (día); brioso (brío); riada (río); viaje (vía ${ }^{20}$.

20 T. Navarro Tomás, 1990, pág. 159. Pero a continuación añade: «Los poetas se sirven del hiato o de la sinéresis, según el tono de la expresión y el lugar que ocupa la palabra, y sobre todo, según las exigencias del verso» (id.: 159). Añade los siguientes ejemplos: 
En coincidencia con estas reflexiones de Bello, P. Álvarez de Miranda lamenta que la OLE10 no haya tenido en cuenta el testimonio contrario de la morfología a la hora de decidir que existe diptongo ortográfico en palabras como desviamos, riamos, riais...

Estimo que se debería haber concedido más espacio y más peso a las consideraciones de índole morfológica, en la línea con los contrastes arriba aducidos (des-vi-ar y des-ví-o frente a cam-biar y cambio). En la no siempre serena polémica que la decisión de 2010 ha suscitado no he visto que nadie señalara la extraña anomalía que se produce, por ejemplo, en el paradigma del presente de subjuntivo del verbo reír, en el que solo la segunda persona del plural, frente a todas las demás formas, resultaría ser monosilábica: riais (con triptongo). Ya que de diptongos y triptongos ortográficos hablamos, podemos decir que el silabeo ortográfico de dicho paradigma verbal es ahora este: rí-a, rí-as, rí-a, ria-mos [y no ri-a-mos], riais [y no ri-ais], rí-an. Pero los silabeos ri-a-mos, ri-ais hacen patente la frontera morfológica que, en todos los hispanohablantes, presentan las otras cuatro formas y el infinitivo re-ír, del mismo modo que la pronunciación de ri-ó - desde 2010 obligatoriamente sin tilde: rioes diferente de la de dio y vio en paralelo con la condición bisilábica (re-ir), frente a la monosilábica (dar, ver) de los infinitivos correspondientes (P. Álvarez de Miranda, 2014: 231-232).

El influjo analógico en la pronunciación que deriva en la conciencia de la frontera morfológica es innegable. De hecho, la articulación con hiato de estos verbos es la más frecuente en la pronunciación estándar de la gente cultivada de amplias zonas del

La hirió Di-ana con su-ave flecha (Hermosilla).

Suave respira el viento, el mar salado (Arriaza).

Porfi-ados al par de la demanda (Maury).

En vano porfiaba Inés (8 sílabas) (Zorrilla).

Mas tu cru-el constancia ya me advierte (Arriaza).

Allí lánguido yace el cruel guerrero (Martínez de la Rosa)

Con que tú sonri-endo lo compones (Juan R. Jiménez).

Yo iré sonriendo y fiel a mi destino (Juan R. Jiménez) 
mundo hispánico. Sin embargo, aun en estos ejemplos de escaso cuerpo fónico, nada impide que en la pronunciación menos pausada y más familiar de cualquier hispanohablante se realicen las articulaciones con diptongos y triptongos sin que se modifique el significado. Es decir, sin que exista alteración del sistema, como se refleja en la transcripción fonológica del siguiente gráfico:

\begin{tabular}{|c|c|c|c|c|c|}
\hline \multicolumn{2}{|c|}{ Fonética } & \multirow[t]{2}{*}{ Fonología } & \multicolumn{2}{|c|}{ Fonética } & \multirow[t]{2}{*}{ Fonología } \\
\hline HIATO & DIPTONGO & & HIATO & TRIPTONGO & \\
\hline [kri.ó] & [krjó] & /krió/ & [kri.áis] & [krjáis] & /kriáis/ \\
\hline [gi.ó] & [gjó] & /gió/ & [gi.áis] & [gjáis] & /giáis/ \\
\hline [li.ó] & [ljó] & /lió/ & [li.áis] & [ljáis], & /liáis/ \\
\hline [li.é] & [ljé] & /lié/ & [li.éis], & [ljéis], & /liéis/ \\
\hline [pi.ó] & [pjó] & /pió/ & [pi.áis], & [pjáis], & /piáis/ \\
\hline [pi.é] & [pjé] & /pié/ & [pi.éis], & [pjéis], & /piéis/ \\
\hline [fi.é] & [fjé] & /fié/ & [fi.éis], & {$\left[\right.$ fjéis] ${ }^{21}$} & /fiéis/ \\
\hline [ri.ó] & [rjó] & /rió/ & [ri.áis] & [rjáis] & /riáis/ \\
\hline [fri.ó] & [frjó] & /frió/ & [fri.áis] & [frjáis] & /friáis/ \\
\hline
\end{tabular}

En la pronunciación de las voces verbales con mayor número de sílabas, tiende a aumentar la realización diptongada, lo que implica que la coincidencia del límite silábico con la frontera morfológica se debilita. «En la morfología verbal se generan alternancias entre diptongo e hiato en los verbos vocálicos de diptongo variable, como sucede en la forma de presente actúo [ak.'tu.o] frente al infinitivo actuar [ak.'twar]; en desvías [des.'bi. as] frente a desviaremos [des.bina.'re.mos]; en oír [o.'ir]; frente a oigo ['oi.go], etc.»22. Esta alternancia se observa asimismo en las

21 Prueba de esta vacilación en la articulación de las secuencias de tres vocales con posible triptongo la hallamos en la NGLEFF. En un mismo párrafo considera triptongo con.fiáis [kon.'fiais] (como miau ['miau] y, poco más abajo, analiza como hiato la forma semejante con.fi.éis [kon.fi.'eis]. Aun así, en este último caso, matiza «al menos en las zonas de ámbito hispánico en las que la tendencia a evitar hiatos es menos frecuente» (NGLEFF: 340).

22 NGLEFF, 2011, pág. 346. El Esbozo recogía esta inestabilidad: «El hiato creciente /i.á/ (fórmula III) en una determinada palabra no impide el diptongo inacentuado en otra palabra derivada de aquella o perteneciente al mismo paradigma que aquella. Así, frente a di-álogo tenemos dia-logar; frente a bi-ólogo, bio-logía; frente 
formas verbales con acento en la vocal fuerte (ac.tu.a.mos $\sim$ ac.tua. mos).

\subsection{En la derivación}

Andrés Bello defendió que los derivados mantienen la frontera morfológica marcada por la raíz:

Las inflexiones y derivaciones conservan la cantidad de sus raíces, como criador, trisílabo, criatura, tetrasílabo, fiaríamos, pentasílabo, derivados de criar y fiar, disílabos; y cambiamiento, endiosado, tetrasílabos, derivados de cambiar disílabo y de Dios monosílabo. En los demás casos la combinación forma naturalmente diptongo; y en todos, si no lo forma, es permitida la sinéresis ${ }^{23}$.

Si la vocal final de la raíz era tónica, suele predominar la articulación hiática de sus derivados. Sin embargo, como las voces derivadas son por lo general más largas que las flexivas, la realización en diptongo no es infrecuente. En cualquier caso, lo que importa subrayar es que, predomine la pronunciación que predomine, tampoco aquí es relevante la frontera morfológica en la articulación de las combinaciones vocálicas (ya sea como diptongos, ya sea como hiatos). En el siguiente gráfico se muestra que los derivados de las palabras de la columna A pueden realizarse como hiatos o como diptongos sin que el significado se vea alterado:

a actú-a, ac-tua-ción; frente a cri-ar, cria-tura; frente a desafi-ar, desafia-ré, etcétera» (RAE, 1973: 52). Respecto a esta última palabra cita un verso octosílabo de Cervantes: «Y de-sa-fia-ré al cristiano» (El gallardo español).

23 Bello, 1835, pág. 50. En esta otra cita incide sobre la misma tesis: «La analojía de las derivaciones determina la cantidad lejítima de las palabras derivadas. Naviero por ejemplo es tetrasílabo, y brioso trisílabo, porque deben añadir una sílaba a los primitivos navío y brío, y por tanto las combinaciones ié, ió son disílabas en aquellas dicciones; pero glorieta es trisílabo, y ambicioso tetrasílabo, porque debe añadir una sílaba a las dicciones primitivas gloria, ambición; de que se sigue que en estos ejemplos las combinaciones ié, ió forman diptongos». (Bello, 1835: 47-48). 


\begin{tabular}{|c|c|c|}
\hline \multicolumn{2}{|r|}{ SILABACIÓN FONÉTICA } & FONOLOGÍA \\
\hline A & B & \\
\hline ví.a & vi.á.ti.co viá.ti.co; vi.a.duc.to via.duc.to & /biá.ti.co/, /bia.dúkto/ \\
\hline dí.a & dia.rio $\sim$ di.a.rio, diur.no $\sim$ di.ur.no & /diá.rio/,/diúr.no/ \\
\hline dú.o & $\begin{array}{l}\text { du.e.to } \sim \text { due.to; du.al } \sim \text { dual; du.a.li.dad } \sim \\
\text { dua.li.dad }\end{array}$ & $\begin{array}{l}\text { /dué.to/, /dual/, } \\
\text { /dua.li.dád/ }\end{array}$ \\
\hline Ma.rí.a & $\begin{array}{l}\text { ma.ri.a.no } \sim \text { ma.ria.no; ma.ri.a.nis.ta } \sim \\
\text { ma.ria.nis.ta }\end{array}$ & $\begin{array}{l}\text { /ma.riá.no/, } \\
\text { /ma.ria.nís.ta/ }\end{array}$ \\
\hline pí.a & pi.a.do.so pia.do.so & /pia.dó.so/ \\
\hline pa.ís & pai.sa.no, pai.sa.je $\mathrm{e}^{24}$ & /pai.sá.no/,/pai.sá.xe/ \\
\hline sa.ú.co & sau.qui.llo & /sau.kí.llo/ \\
\hline frí.o & frio.le.ra & /frio.lé.ra/ \\
\hline lí.o & lio.so $\sim$ li.o.so, lian.te $\sim$ li.an.te & /lió.so/, /lián.te/ \\
\hline brí.o & brio.so $\sim$ bri.o.so & /brió.so/ \\
\hline naví.o & na.vie.ro $\sim$ na.vi.e.ro & /na.bié.ro/ \\
\hline va.rí.a & va.ria.do va.ri.a.do; va.rio va.ri.o & /ba.riá.do/, /bá.rio/ \\
\hline por.fí.o & por.fiar $\sim$ por.fi.ár; por.fi.a.do por.fia.do & /por.fiár/,/por.fiá.do/ \\
\hline a.hú.man & ahu.ma.do; ahu.mar & /au.má.do/,/au.már/ \\
\hline $\begin{array}{l}\text { héro.e, } \\
\text { he.ro.í.na }\end{array}$ & he.roi.co $\sim$ he.ro.i.co ${ }^{25}$ & /e.rói.ko/ \\
\hline
\end{tabular}

La conciencia morfológica que persiste en palabras resultantes de la prefijación y de la composición que dan como resultado secuencias de vocal cerrada y vocal abierta tampoco resulta fonológicamente distintiva. De hecho, se suelen realizar mayoritariamente como diptongos, rompiendo la frontera morfológica:

24 La NGLEFF relaciona esta alternancia con la variación geográfica ("dependiendo de las zonas, se prefiere una u otra articulación" (NGLEFF: 346).

25 «Asimismo, en el caso de heroico, que muchas veces se realiza he-ró-i-co, con una frontera silábica y morfológica que hereda de hé-ro-e, la Academia se había decantado en el diccionario, al no ponerle tilde, por la opción diptongal, es decir, por he-roi-co como trisílabo llano y no como tetrasílabo y esdrújulo» (P. Álvarez de Miranda, 2016: 231). 


\begin{tabular}{|l|l|l|}
\hline \multicolumn{2}{|c|}{ SILABACIÓN FONÉTICA } & \multicolumn{1}{c|}{ FONOLOGÍA } \\
\hline & \multicolumn{1}{|c|}{ B } & \\
\hline anti- & an.ti.es.té.ti.co $\sim$ an.ties.té.ti.co & /an.ties.té.ti.ko/ \\
\hline archi- & ar.chi.o.bli.ga.do ar.chio.bli.ga.do & /ar.chio.bli.ga.do/ \\
\hline bi- & bi.a.nuál bia.nuál; & /bia.nuál;/ \\
\hline boqui- & bo.qui.a.biér.to bo.quia.biér.to & /bo.kia.biér.to/ \\
\hline di- & di.ók.si.do diók.si.do & /diók.si.do/ \\
\hline multi. & mul.ti.ú.so mul.tiú.so & /mul.tiú.so/ \\
\hline tri- & tri.án.gu.lo trián.gu.lo & /trián.gu.lo/ \\
\hline cuatri- & cua.tri.é.nio cuat.rié.nio & /kua.trié.nio/ \\
\hline semi- & se.mi.hun.dí.do se.mihun.dí.do & /se.miun.dí.do / \\
\hline peri- & pe.ri.ós.tio pe.riós.tio & /pe.riós.tio / \\
\hline poli- & po.li.é.dro po.lié.dro & /po.lié.dro/ \\
\hline pluri- & plu.ri.em.plé.o plu.riem.plé.o & /plu.riem.plé.o/ \\
\hline
\end{tabular}

En conclusión, la conciencia de la frontera morfológica no es tan fuerte como para imponer una división silábica constante (y, menos aún, relevante) entre las secuencias vocálicas en las que el acento no recae sobre la vocal cerrada. En algunos casos, predomina incluso la realización fónica diptongada (tautosilábica) sobre la pronunciación no diptongada (heterosilábica). Si esto es así, si el límite morfológico no crea una frontera fonológica pertinente, $y$, si ni siquiera establece un límite articulatorio respetado de forma constante, queda claro que no puede convertirse en un criterio aplicable a la ortografía.

\section{Nuevos problemas}

\section{1 ¿Por qué no se deja libertad de escritura?}

Algunas de las críticas más comunes que se dirigen contra la OLE10 se focalizan en la obligatoriedad de las nociones de diptongo ortográfico e hiato ortográfico. Estas nociones habían sido asentadas con toda claridad por la OLE99 (cf. pág. 43). Sin embargo, dejaba libertad en el uso de la tilde:

A efectos ortográficos, son monosílabos las palabras en las que, por aplicación de las reglas expuestas en los párrafos anteriores, se considera que no existe hiato - aunque la pronunciación así parezca indicarlo-, sino diptongo o triptongo. Ejemplos: fie (preté- 
rito perfecto simple del verbo fiar), hui (pretérito perfecto simple del verbo huir), riais (presente de subjuntivo del verbo reír), guion, Sion, etc. En este caso es admisible el acento gráfico, impuesto por las reglas de ortografía anteriores a estas, si quien escribe percibe nítidamente el hiato $\mathrm{y}$, en consecuencia, considera bisílabas palabras como las mencionadas: fié, huí, riáis, guión, Sión, etc. (OLE99: 46).

Las posiciones críticas van desde quienes exponen una simple preferencia ${ }^{26}$ hasta quienes acuden a una argumentación detallada. Veamos algunas de las razones.

\subsubsection{La dualidad de articulaciones aconseja libertad de acentuación}

Esta primera crítica se halla bien formulada por Javier Marías:

Si un número muy elevado de hablantes percibe todos estos vocablos como bisilábicos con hiato, y no como monosilábicos con diptongo, ¿a santo de qué impedirles la opcionalidad en la escritura? La RAE parece tenerle pánico a la posibilidad de elegir en cuestión de tildes (que es algo menor y que no afecta a la sacrosanta "unidad de la lengua") (J. Marías: 2011).

En el mismo hecho incide L. Gómez Torrego, a la vez que realiza una propuesta:

Si se trataba de dar una regla que abarcara toda la realidad de pronunciaciones diferentes según las zonas, quizá hubiera sido más útil haber mantenido la tilde en estas palabras diciendo algo así como: "Dado que tales palabras se pronuncian como hiatos en unas zonas del ámbito hispánico, y como diptongos en otras zonas, se recomienda seguir poniendo la tilde en ellas" (L. Gómez Torrego, 2013: 69.).

26 «Sigo creyendo que hubiera sido mejor dejar las cosas como estaban, o, si se quiere - no se me acusará de misoneísta emocional o a ultranza-, como se decidió ponerlas en 1999» (P. Álvarez de Miranda, 2016: 231). 
Una ortografía que pretenda cumplir con su obligación de ser coherente y de realizar unas normas comunes para toda la comunidad hispanohablante no puede ni debe asumir esta propuesta:

a) Es contradictoria. Permitiría una praxis en la escritura que entra en contradicción con la regla previamente establecida. Si se sostiene que las palabras fie, hui, riais, guion, Sion "a efectos ortográficos, son monosílabos" (OLE99:46), la única opción coherente es proponer por norma que no se acentúen gráficamente, pues los monosílabos no llevan tilde. La permisión de la OLE99 era contradictoria ${ }^{27}$, y las decisiones contradictorias no pueden tener larga vida en la ortografía ${ }^{28}$.

b) Apela al criterio de la percepción subjetiva de los hablantes. La ortografía tiene la obligación de proponer normas unívocas y unitarias en la escritura, mientras que tomar como criterio la percepción de los hablantes aboca necesariamente a la inseguridad y a la dispersión.

c) «Si se trataba de dar una regla que abarcara toda la realidad de pronunciaciones diferentes según las zonas» la solución no es la pronunciación de una de ellas (coincidente, una vez más, con la norma de España), como de hecho propone Gómez Torrego.

\subsubsection{La práctica de los escritores cultos}

Junto al argumento anterior, Gómez Torrego aduce:

27 Se podría entender como una permisión transitoria para que los usuarios se fueran acostumbrando a la nueva norma.

28 Un caso semejante de contradicción de la OLE99 es el que afecta al alfabeto. En la enumeración de las letras se incluyen la "ch" (che) y la "ll" (elle), e, inmediatamente de debajo del gráfico, se dice: «En realidad, ch y ll son dígrafos, signos ortográficos compuestos de dos letras» (OLE99: 2). Esta contradicción, comprensible si se conocen las causas que la generaron, no podía ser mantenida largo tiempo. La OLE10 restablece la coherencia eliminando estos dígrafos del alfabeto (OLE10: 63-65). 
De esta forma se hubiera reconocido su diversidad fónica, pero no se hubiera eliminado una tilde que todos los escritores cultos ponían en estas palabras (Ibid.).

Es natural y esperable que los escritores colocaran con normalidad la tilde en este tipo de palabras, pues hasta 1999 era obligatorio y desde 1999 estaba permitido. Si se refiere al pasado, la justificación es endeble; si, por el contrario, desea aludir a la oposición de algunos escritores después de la aparición de la OLE10, ese es un problema distinto.

\subsubsection{No se hubiera producido polémica mediática ${ }^{29}$}

Como es notorio, la Academia no puede dejarse guiar por las reacciones y las guerras mediáticas, que en los casos de ortografía se hallan generalmente provocadas por la tendencia subjetiva a mantener invariable lo que se aprendió como dogma. Precisamente, cuando la OLE99 permitió tildar o no a los llamados monosílabos ortográficos (la solución que ahora estos críticos proponen), las acusaciones fueron contundentes ( $y$, lo que es peor, aquellas críticas sí estaban cargadas de razón).

\subsubsection{Los conceptos de diptongo ortográfico e hiato ortográfi- co no se corresponden con la definición académica \\ Son palabras literales de la crítica formulada por Gómez To- rrego:}

Además, hubiera ahorrado los conceptos de diptongo gráfico e hiato gráfico, que no se corresponden con la definición académica. En consecuencia, había los mismos motivos para mantener la tilde que para eliminarla; y en estos casos, lo mejor hubiera sido no cambiar lo que la tradición ya había fijado" (L. Gómez Torrego, 2013: 69).

29 «Dicho de otra manera: no se hubiera producido ninguna polémica mediática, pues incluso los que creían pronunciar una sola sílaba, las venían acentuando» (L. Gómez Torrego, 2013: 69). 
No es en modo alguno cierto que las nociones de diptongo, triptongo e hiato ortográfico no se correspondan con la definición académica. Así son expresamente definidos por la OLE10 en las páginas 235-237 (vid. supra. §2.6).

Por lo demás, ha quedado claro que no existen los mismos motivos para mantener la tilde que para eliminarla. La decisión de eliminarla (truhan) está fundada en criterios fonológicos (en hechos del sistema común a todos los hispanohablantes). La opción de mantener la tilde (truhán) implicaba imponer una norma (la castellana) sobre otra (la centroamericana). La alternativa de dejar libertad de acentuación (truhán truhan) hubiera sido contradictoria con los principios y desaconsejable en la práctica (las normas ortográficas deben ser unívocas).

\section{2 ¿Obliga la Academia a pronunciar guion y truhan como diptongos?}

Una de las críticas dirigidas contra la OLE10 supone que la escritura de estos monosílabos incita a pronunciarlos como diptongos. Así la formula Javier Marías:

En cuanto a "guié" o "crié", si se me vetan las tildes y se me impone "guie" y "crie", se me está indicando que esas palabras las debo decir como digo "pie", y no es mi caso, y me temo que tampoco el de ustedes. Hagan la prueba, por favor. Tampoco digo "guió" y "crió" como digo "vio" o "dio", a lo que se me induce si la única manera correcta de escribirlas es ahora "guio" y "crio" (en la Ortografía de 1999 poner o no esas tildes era optativo, y no alcanzo a ver la necesidad de privar de esa libertad) (J. Marías, 2011).

Tanto la OLE99 como la OLE10 insisten en que los nuevos conceptos de diptongo, triptongo e hiato ortográficos son independientes de la pronunciación concreta tautosilábica o heterosilábica. Para representar estas nuevas entidades ortográficas se adopta la escritura más neutra, la menos marcada, la que trans- 
cribe los valores fonológicos. Se ha visto con numerosos ejemplos que en las secuencias de vocal cerrada y vocal abierta o vocal abierta y vocal cerrada átona solo es relevante la posición del acento /fie-fie/, /pio-pio/, /rio-rio/. Se ha mostrado asimismo que cuando el acento recae sobre la vocal abierta, carece de relevancia que dicha secuencia se articule como hiato o como diptongo. La realización concreta como hiato o como diptongo puede ser un hecho de habla (debido, por ejemplo, a la velocidad de la articulación) o de norma (en unas zonas predomina la articulación como hiato [fi.e] - por ejemplo, España - y en otras, la realización monosilábica [fje] - por ejemplo, en México y Centroamérica-); pero no de sistema. La ortografía refleja valores de sistema, no hechos de norma.

Si las palabras que hoy se hallan en litigio se escribieran como antes de 1999 (guión, truhán, Sión, fió, lió, guié, riáis...) debería interpretarse necesariamente que son bisílabas ${ }^{30}$ y que las vocales forman un hiato tanto fonético (lo que podría ser cierto o falso, según las circunstancias) como fonológico (lo que siempre sería falso). Por el contrario, la escritura guio, fio, lie, guie... marca únicamente lo relevante (la posición del acento - frente a guío, fío, lie, guíe-) y se abstiene de representar el hecho fonético no relevante de si se pronuncian como hiatos o como diptongos.

$\mathrm{Al}$ adoptar la alternativa menos marcada, la que mejor interpreta los valores fonológicos, la Academia es congruente con la forma como había resuelto previamente otros casos de diptongos ortográficos:

- La ortografía tan debatida de las secuencias-uí-. Los más articulaban como diptongo suizo, descuido, juicio, fuiste... (por las que se proponía escritura sin tilde), y como hiatos jesu-ita, destru-ir, destru-ido, altru-ista... (para las que se defendía escritura con tilde). Claro está, había pronunciaciones que alteraban estos hábitos y, además, casos dudo-

30 La presencia de la tilde implica necesariamente reconocer que la palabra es bisílaba, pues los monosílabos no se tildan. Se convierte en una marca positiva de hiato. 
sos (beduino, babuino, genuino, arruino, juicio, lingüista...). Como se ha visto ( $c f . \S 2.2)$, en 1952 se adoptó la sabia decisión de considerarlos "p r á c t i c a m e n t e como diptongos en todos los casos" (Norma 23. ㅁ), lo que es lo mismo que decir 'diptongos ortográficos'. Lo que aquí se destaca es que, sin ser consciente, la RAE efectuó un análisis fonológico (se atuvo a lo distintivo) y propuso la escritura más neutra para representarlo: suizo, descuido, juicio, jesuita, destruido, construir... Quienes pronunciaban jesuita como hiato ([xe.su.í.ta]) lo siguieron haciendo con independencia de que la escritura no diera cuenta de este hecho que no es distintivo.

- La ortografía de las palabras con secuencias vocálicas uo, ua, ue, io, ia, ie en sílaba postónica (ambiguo, superfluo, tenue...), así como algunos casos de palabras llanas con $\boldsymbol{a} i$, oi, ei (heroico, prosaico, oleico...) presentaban problemas de alternancia hiato $\sim$ diptongo en la realización. Si se escribieran con tilde (su.pér.flu.o), tendríamos que interpretar que el hiato es obligatorio; por el contrario, si se adopta una escritura neutra que atiende a los valores fonológicos (su.per.fluo), no crea ningún deber de pronunciar la secuencia como hiato o como diptongo. En 1974, se decidió “a efectos ortográficos, cualquiera sea su pronunciación real”, considerarlos diptongos. Pues bien, en aquel momento se adopta la escritura más simple, la no marcada, la que reflejaba los valores distintivos, la escritura sin tilde (superfluo, vacua, tenue, prosaico, heroico, oleico), sin que esto implicara una recomendación de pronunciar diptongo.

\section{Secuencias vocálicas /ui, iu/}

Como expresaba el Esbozo, «las vocales /i, u/ aparecen en posición inmediata la una de la otra, tautosilábica o heterosilábica, en grupo acentuado o inacentuado» (RAE, 1973: 54). En apariencia, no parecen tener diferencias con el comportamiento de otros 
diptongos. Sin embargo, frente a ellos, presentan peculiaridades fonéticas, fonológicas y ortográficas.

\subsection{Problemas fonéticos de las secuencias vocálicas /ui, iu/}

Desde una perspectiva fonética, surgen varios problemas relativos a su realización como diptongos o como hiatos, y, en el caso de realizarse como diptongos, dificultades para determinar si son crecientes o decrecientes.

\subsubsection{Carácter creciente o decreciente de los diptongos /ui, iu/}

Frente al comportamiento del resto de los diptongos, aquí no resulta siempre fácil determinar su nuclearidad. En los diptongos formados por estas vocales no es posible acudir al criterio de mayor abertura para determinar cuál es el núcleo (pues ambas son cerradas). Como se da siempre un cambio de timbre (anterior > posterior; posterior > anterior), el acento prosódico puede convertirse en marca de nuclearidad: $u i$ sería descendente, $u i$, ascendente. Aunque no existen posturas extremas, los autores se alinean en dos opciones:

1) No forman diptongos crecientes ni decrecientes, pues no existe un núcleo estable. Esta posición es defendida por la RAE en el Esbozo de una nueva gramática de la lengua española (1973):

La única diferencia es que, en el caso de la sucesión /u i/ o /i u/, resulta imposible determinar su carácter creciente o decreciente. En el diptongo /ai/, por ejemplo, la vocal /a/ y solo ella es el núcleo. En el diptongo /ui/, en cambio, tanto / $\mathrm{u} /$ como /i/ pueden funcionar, alternativamente, como núcleo o como satélite [ui], [wi], y lo mismo ocurre con el diptongo /iu/. Diremos todo lo más que, por analogía con los criterios utilizados con la clasificación de los grupos del $\S$ 1.4.6 $6^{\mathrm{a}}$, los diptongos /uí/ [wí] y /iú/ [jú], con la vocal que funciona como núcleo situada detrás, como en /iá/, son crecientes, y los diptongos /úi/ [úi] y /íu/ [íun], con el núcleo delante, como en /ái/, decrecientes. Cuando el diptongo es inacentuado, o cuando las dos 
vocales forman hiatos acentuados o inacentuados, falla el criterio basado en la posición del núcleo silábico y solo teniendo en cuenta la mayor frecuencia en el uso de uno u otro diptongo cabe hablar, también por analogía, de que una sucesión como $h u$-i-do es creciente o decreciente (RAE, 1973: 54-55).

Antonio Hidalgo y Mercedes Quilis acuden a un criterio alternativo para determinar en estas combinaciones de vocales cerradas cuál es el núcleo: aquella vocal que sea más intensa. Sin embargo, al considerarlo un criterio inestable, proponen no hablar en estos casos de diptongos crecientes y decrecientes:

Es posible también la confluencia de /i/ con /u/ y viceversa: si se produce esta circunstancia, al presentar ambas vocales el mismo grado de abertura, el núcleo lo ocupará la vocal que reciba el acento de intensidad, hecho que puede variar en función del hablante, la situación o el dialecto; por esta razón no es posible hablar en estos casos de diptongos crecientes o decrecientes. Ejemplos de estas agrupaciones serían las distintas pronunciaciones de /bíuda/ o /biúda/, /fuí/ o /fúi/ (A. Hidalgo - M. Quilis, 2002: 130-131).

2) El núcleo es el segundo elemento del diptongo, aunque se exceptúan algunas realizaciones dialectales o del habla. T. Navarro Tomás se inclina por esta visión más simple ${ }^{31}$ :

31 M.A. Caro se suma a esta opinión, aunque aporta numerosas excepciones:

Regla 3 $3^{\underline{a}}$ ) "Si se combinan las vocales $i$, $u$, que son débiles en igual grado, el acento va en la que se halle en segundo lugar; sea que haya diptongo: cuíta, viúda, fui, Güi, triunfo, o que no lo haya: huí, hiúlco, instruído.

Por excepción llevan el acento en la primera, con diptongo, cocuy, muy, y sin él: Túy, y Espelúi (según la Academia; Sicilia diptonga en Túy), flúido, Ríu. Por analogía ha caído en desuso la acentuación etimológica de búitre, cúido, y víuda, y drúida, gratuíto (v. Cuervo, Ap. §119). Sicilia pronunciaba Ruy (ed. París, III, 106), pero la pronunciación corriente es la misma de Ruíz. Cita el mismo Sicilia con acento en la $u$, los nombres extranjeros Dupuy y Maupertuis (III, 149). (M. A. CARO, 1980 [1887]: 151-152). 
«En los grupos $i u$, ui predomina siempre como elemento principal del diptongo la segunda vocal, reduciéndose la primera a semiconsonante» (T. Navarro Tomás: 1990: 65). El volumen de Fonética y fonología de la Nueva gramática de la lengua española, de la RAE y ASALE (2011), opta asimismo por considerarlos crecientes, apoyándose en una mayor tendencia en la pronunciación ${ }^{32}$ :

Un diptongo puede estar integrado también por dos vocales altas distintas, como ui en cui.das o iu en interviú. Dado que la lengua española favorece claramente la diptongación creciente, cuando dos vocales altas aparecen en la misma sílaba (bui.tre, ciu.dad, viu. do), se suele considerar que constituyen un diptongo creciente y, si requieren tilde, esta se coloca sobre la segunda vocal (a.cuífero, in.ter.viú) (NGLEFF, 2011: 332-333).

\subsection{Hiato y diptongo en las secuencias /ui/}

\subsubsection{Hiato y diptongo en las secuencias /uíl}

Señalaba el Esbozo de la RAE que en las voces que incorporan esta secuencia con /í/ tónica hallamos frecuentes combinaciones como hiatos. Se encuentran en formas de verbos en $-u i r^{33}$ (destru-í, destru-ido, conclu-í, conclu-ido, atribu-í, atribu-ido, hu-í, $h u$-ido, derru-í, derru-ido...), en voces de formación romance con sufijo que comienza por /i/ tónica (jesu-ita, altru-ismo, casu-ista), palabras de origen latino (gratu-ito, pru-ina, ru-ina, ru-in) y términos de origen vario (fu-ina, bedu-ino...). Sin embargo, reconoce que hay variación entre la pronunciación como hiato o como diptongo. Basta, en efecto, un aumento del cuerpo fónico para

32 Pero, a continuación, añade matizando lo dicho previamente:

No obstante, en el habla, es posible realizar la combinación de las dos vocales como diptongo creciente (cuita ['kui.ta]) o como diptongo decreciente (cuita ['kui. ta]) en función de diversos factores (Ibidem). 
que el hiato se relaje: jesuítico, casuístico. Predomina el diptongo cuando la secuencia /ui/ es átona (cui-dado, cui-tado, superflui-dad, distribui-dor), incluso cuando se relaciona con raíces de realización normalmente heterosilábica (rui-noso, ruin-dad, gratui-dad, hui-dizo).

La Fonética y fonología de la Nueva gramática de la lengua española (2011) se expresa en términos parecidos:

Igualmente, la combinación de las dos vocales altas en el grupo $u i$ o en el grupo iu presenta una considerable variación. Buitre o cuita suelen realizarse como diptongo; en cambio, concluido, diurno o jesuita son pronunciadas frecuentemente con hiato, aunque en el Perú y en otros países el diptongo es más usual en jesuita y diurno que en construí o concluido. Es muy difícil regular estas vacilaciones, dado el grado libertad de los hablantes ante los factores que condicionan la aparición de uno u otro tipo de realización (NGLEFF, 2011: 337).

\subsubsection{Vacilación del acento en las secuencias /ui/}

Aunque las sílabas tónicas que incorporan la secuencia /ui/ tienden a intensificar el segundo segmento ([wí]), se hallan términos en los que el acento prosódico recae normalmente sobre la /u/: es el caso de algunos nombres de lugar: Espeluy (Jaén), Bernuy (Ávila y Segovia), Beranuy (Huesca), Tuy (Pontevedra), así como algunos topónimos catalanes (Cf. RAE, 1973: § 1.4.11c.).

En el habla popular de algunas regiones de España y de América se acentúa normalmente la /u/: muy /múi $/{ }^{34}, \operatorname{cocuy}^{35}$ (bebida) /

34 «En cuanto a muy es interesante observar que la apócope popular no da $m i$ sino $m u$ : 'una casa $m u$ grande; un bicho $m u$ feo'» (J. Casares, 1951: §31: 405). «Para nosotros, la tan discutida palabra 'muy' se pronuncia [múi], lo cual se prueba en la pronunciación enfática: 'muy, pero que MUY bien' [mú:i ßjén]» (M. J. Canellada - J. K. Madsen, 1987: 50).

35 «Obsérvese que en el caso de las palabras terminadas en - $u y$, como cocuy, cuy, huy o tepuy, la escritura con -y refleja la pronunciación [úi] de dicha terminación; si en esta secuencia fuese tónico el segundo elemento, pronunciándose [uí], el 
kokúi/, cuy (cobaya) /kúi/, jhuy! /úi/, tepuy /tepúil, druida /drúida/, fluido $^{36}$ /flúido/, buitre /búitre/, cuida /kúida/, descuido/deskúido/, cuita /kúita/...

Esta variabilidad en la posición del acento en la secuencia /ui/ nos muestra que la mayor frecuencia de su posición en el segundo elemento vocálico es cuestión de norma, no de sistema.

\subsubsection{Fonología de las secuencias vocálicas /ui/}

\subsubsection{Cuatro realizaciones}

Las secuencias en las que intervienen dos vocales débiles poseen un estatuto fonológico singular. Como se puede observar en los siguientes cuadros, ninguna de las conmutaciones posibles produce cambios de sentido. No son pertinentes ninguno de los dos siguientes parámetros:

1) ni la diferencia diptongo/hiato,

2) ni el cambio de posición del acento.

El hecho de que algunas pronunciaciones sean erráticas, otras apenas registradas y otras sean más normales no constituye un hecho pertinente: lo verdaderamente decisivo es que en ningún caso ninguno de estos dos rasgos se muestra distintivo para di-

fonema /i/ final tendría que escribirse con i: alauí, benjuí, tui o cui (estas dos últimas voces sin tilde por ser monosílabas). Es excepción el adverbio muy, escrito tradicionalmente con $-y$, aunque su pronunciación general sea [muí] (v. cap. I, §6.1.2.1.2b)]». (OLE10: 234, §3.4.2).

36 Las dudas en la articulación y en la escritura de druida y fluido (sustantivo) alcanzaron también a la ortografía académica: «La Academia, por su parte, también se mostró fluctuante, no solo con el caso de fluido, sino también en otro parejo, el de druida; y es curioso observar que no coinciden los períodos en que ambas voces aparecen con tilde. Druida la tuvo desde el comienzo hasta 1803. Mientras carecía de ella fluido, que no la consiguió hasta 1832. En 1884 se suprimió la tilde en ambos casos, pero el régimen de igualdad duró bien poco: druida continúa desde entonces sin tilde y flúido, que la recobró en 1899, sigue gozando de ella... por ahora» (J. Casares, 1951, §31: 404-405). Un año más tarde la Academia decide que, a efectos ortográficos, las secuencias -ui-son siempre diptongos, con lo que tanto fluido como druida no se deben acentuar. 
ferenciar el significado de al menos un par mínimo. Las variaciones fónicas de la voz buitre ([bú.i.tre] [bu.í.tre] [bwí.tre] [búi. tre]) no alteran el significado. En la mayoría de circunstancias, el predominio de una realización corresponde a hechos de norma, no de sistema del español. Que predomine una $u$ otra realización, que alguna variante no se registre mientras que otra puede constituir la realización más frecuente se puede deber a distintos factores; es cuestión de uso o de norma; pero no de sistema ${ }^{37}$. La ortografía refleja valores fonológicos, por lo que una misma escritura puede representar a las cuatro pronunciaciones:

\subsubsection{Verbos en -uir}

Existe un modelo de conjugación verbal ${ }^{38}$ que forma una secuencia vocálica ui en la unión de la base con la desinencia. A él pertenece una cantidad bastante poblada de verbos como fluir, huir, fruir, luir, muir, afluir, argüir, construir, constituir, contribuir, derruir, destituir, destruir, disminuir, distribuir, estatuir, imbuir, inmiscuir, instituir, prostituir, recluir, restituir, retribuir, sustituir. Algunos verbos de este grupo, huir, fluir, fruir, luir y muir, presentan un cuerpo fónico menor que el resto (dan lugar a formas

37 «[INFORMACIÓN ADICIONAL: Las voces que contienen secuencias de dos vocales cerradas distintas (/ui/, /iu/) en las que la tonicidad vacila entre una y otra vocal según los hablantes - como ocurre en [buítre] o [búitre], [fluído o flúido], etc. (v. §3.4.2) - son las únicas que constituyen una excepción a este principio. Cuando estas palabras deben llevar tilde según las reglas de acentuación, la doble posibilidad prosódica señalada no se traduce en la existencia de dos variantes gráficas acentuales, sino que la tilde se coloca convencionalmente siempre sobre la segunda vocal (v. § 3.4.2.1.3b). Así, se escribe siempre cuídate (imperativo de segunda persona del singular para los hablantes que no vosean), aunque esta grafía pueda corresponder oralmente a dos pronunciaciones distintas: [kuídate] o [kúidate]. El hecho de ser muy pocas las palabras a las que afecta esta vacilación prosódica - por lo demás, bastante sutil y poco perceptible en la mayoría de los casos- y muchas menos aún aquellas en las que tendría repercusiones gráficas como consecuencia de la aplicación de las reglas de acentuación, unido a que esa diferencia de pronunciación nunca es distintiva, son razones que justifican sobradamente esta excepción]». (OLE10: 229).

38 Aparece clasificado con el número 24 en la Nueva gramática de la lengua española. 


\begin{tabular}{|c|c|c|c|c|c|}
\hline \multicolumn{2}{|c|}{ A (hiato) } & \multicolumn{2}{|c|}{ B (diptongo) } & \multirow{2}{*}{$\begin{array}{c}\text { Fonología } \\
\text { /'ui/ }\end{array}$} & \multirow[t]{2}{*}{ Ortografía } \\
\hline [ú.i] & [u.í] & [wí] & [úi] & & \\
\hline [bú.itre] & [bu.ítre] & [bwítre] & [búitre] & /'buitre/ & buitre \\
\hline [bú.ido] & [bu.ído] & [bwído] & [búido] & /'buido/ & buido \\
\hline [sú.ido] & [su.ído] & [swído] & [súido] & /'suido/ & suido \\
\hline [rú.ina] & [ru.ína] & [rwína] & [rúina] & /'ruina/ & ruina \\
\hline [xenú.ino] & [xenu.íno] & [xenwíno] & [xenúino] & /xe'nuino/ & jenuino \\
\hline [bedú.ino] & [bedu.íno] & [bedwíno] & [bedúino] & /be'duino/ & beduino \\
\hline [jesú.ita] & [jesu.íta] & [jeswíta] & [jesúita] & /je'suita/ & jesuita \\
\hline [pingú.ino] & [pingu.íno] & [pingwíno] & [pingúino] & /pin'güino/ & pingüino \\
\hline [fortú.ito] & [fortu.íto] & [fortwíto] & [fortúito] & /for'tuito/ & fortuito \\
\hline [rú.ido] & [ru.ído] & [rwído] & [rúiddo] & /'ruido/ & ruido \\
\hline [jú.iӨio] & [ju.í日io] & [jwí日io] & [júi $\theta$ io] & /'juicio/ & juicio \\
\hline [kú.ida] & [ku.ída] & [kwída] & [kúida] & /'kuida/ & cuida \\
\hline [altrú.ista] & [altru.ísta] & [altrwísta] & [altrúissta] & /al'tuista/ & altruista \\
\hline [flú.ido] & [flu.ído] & [flwído] & [flúíido] & /'fluido/ & fluido \\
\hline [sú.izo] & [su.ízo] & [swízo] & [súizzo] & /'suizo/ & suizo \\
\hline [tú.it] & [tu.ít] & [twít] & [túit] & /'tuit/ & tuit \\
\hline
\end{tabular}

con monosílabos ortográficos: hui, huis, huid, flui, fluis, fluid...). Entre la base y la desinencia pasa una frontera morfológica que, en ciertas formas, aparece reforzada con una consonante antihiática/y/: construye, destruye, confluye...

Por razones morfológicas, el acento afecta a la desinencia. De ahí que, cuando intensifique la secuencia vocálica, siempre recae sobre la /í/: construí construimos, construid... Sin embargo, tampoco aquí es relevante la articulación como hiato o como diptongo. Alternan las dos posibilidades sin valor distintivo:

\begin{tabular}{|c|c|c|c|}
\hline A & \multicolumn{2}{|c|}{ B } & \\
\hline$\varnothing$ & $\begin{array}{l}\text { [kons.tru.í] } \\
\text { [kons.tru.íd] } \\
\text { [kons.tru.i.ré.mos] }\end{array}$ & $\begin{array}{l}\text { [kons.trwí]' } \\
\text { [kons.trwíd] } \\
\text { [kons.trwi.ré.mos] }\end{array}$ & $\begin{array}{l}\text { construí } \\
\text { construid } \\
\text { construiremos }\end{array}$ \\
\hline$\varnothing$ & $\begin{array}{l}\text { [kon.flu.í] } \\
\text { [kon.flu.íd] } \\
\text { [kon.flu.í.an] }\end{array}$ & $\begin{array}{l}\text { [kon.flwí] } \\
\text { [kon.flwíd] } \\
\text { [kon.flwí.an] }\end{array}$ & $\begin{array}{l}\text { confluí } \\
\text { confluid } \\
\text { confluían }\end{array}$ \\
\hline$\varnothing$ & $\begin{array}{l}\text { [des.tru.í] } \\
\text { [des.tru.íd] } \\
\text { [des.tru.i.ré.mos] }\end{array}$ & $\begin{array}{l}\text { [des.trwí] } \\
\text { [des.trwíd] } \\
\text { [des.trwi.ré.mos] }\end{array}$ & $\begin{array}{l}\text { destruí } \\
\text { destruid } \\
\text { destruiremos }\end{array}$ \\
\hline
\end{tabular}


El comportamiento de las formas verbales más simples (huir, fluir, fruir y muir) no es distinto. Aunque es más frecuente y normal el hiato, la articulación como diptongo no provoca cambio de sentido. De hecho, es común pronunciar las secuencias como diptongo en las combinaciones átonas: fluirán, fluiríamos, huiremos, huirían...

\subsubsection{En final de palabra}

Las palabras agudas terminadas en la secuencia vocálica /ui/ presentan dos posibilidades: que la intensidad incida sobre la /u/ o sobre la /i/. El sistema ortográfico diferencia esta doble posibilidad de la ubicación del acento cuando el diptongo se da en posición final de palabra:

Obsérvese que en el caso de las palabras terminadas en -uy, como cocuy, cuy, huy o tepuy, la escritura con -y refleja la pronunciación [úi] de dicha terminación; si en esta secuencia fuese tónico el segundo elemento, pronunciándose [uí], el fonema /i/ final tendría que escribirse con i: alauí, benjuí, tui o cui (estas dos últimas voces sin tilde por ser monosílabas) (OLE10: 234).

\begin{tabular}{|c|c|c|c|c|}
\hline & \multicolumn{2}{|c|}{ /uí/ (grafía "ui-uí") } & \multicolumn{2}{|c|}{ /úi// } \\
\hline & [u.í] & [wí] & [ú.i] & [úi] \\
\hline alauí & [ala.u.í] & [alawí] & [Ø] & [Ø] \\
\hline benjuí & [benxu.í] & [benxwí] & [Ø] & [Ø] \\
\hline concluit & [konklu.í] & [konklwí] & [Ø] & [Ø] \\
\hline instruí & [instru.í] & [instrwí] & [Ø] & [Ø] \\
\hline influí & [influ.í] & [inflwí] & [Ø] & [Ø] \\
\hline chogüí & [ĉogu.í] & [ĉogwí] & [Ø] & [Ø] \\
\hline flui & [flu.í] & [flwí] & [Ø] & [Ø] \\
\hline frui & [fru.í] & [frwí] & [Ø] & [Ø] \\
\hline mui & [mu.ín & [mwí] & [Ø] & [Ø] \\
\hline lui & [lu.í] & [lwí] & [Ø] & [Ø] \\
\hline hui & [u.í] & [wí] & [Ø] & [Ø] \\
\hline
\end{tabular}

Como en casos anteriores, en esta posición final de palabra recobra la pertinencia la ubicación de la vocal tónica, no así su realización como hiato o como diptongo. Es el caso de voces 
como alauí, benjuí, concluí, instruí, influí, chogüi, flui, frui, mui, hui. Las últimas cinco palabras no llevan tilde por ser monosílabos.

Por el contrario, la escritura con " $y$ " final indica que la intensidad recae sobre la primera vocal: cocuy, tepuy, Ruy, huy:

\begin{tabular}{|c|c|c|c|c|}
\hline \multicolumn{2}{|c|}{ /uí/ (grafía " $\left.u i-u i^{\prime \prime}\right)$} & \multicolumn{2}{|c|}{ /úi/ (grafía " $u y$ ") } & \\
\hline [u.í] & [wíl] & [ú.i] & [úi] & \\
\hline [Ø] & [Ø] & [kokú.i] & [kokúi]] & cocuy \\
\hline [Ø] & [Ø] & [tepú.i] & [tepúi] & tepuy \\
\hline [Ø] & [Ø] & [r̂́.í.] & [rúui] & Ruy \\
\hline [Ø] & [Ø] & [ú.i] & [úi]] & huy \\
\hline
\end{tabular}

El roedor, semejante a una cobaya, recibe dos grafías cuy y cui. Según la primera, que parece la más asentada morfológicamente (plural cuyes, y diminutivo cuyitos), el acento recae en la $/ \mathrm{u} /$ :

\begin{tabular}{|l|l|l|l|l|}
\hline$[\varnothing]$ & {$[\varnothing]$} & [kú.i] & [kúi $]$ & cuy \\
\hline
\end{tabular}

Por el contrario, la grafía cui (plural cuis) indica que la vocal tónica es la /i/.

\begin{tabular}{|l|l|l|l|l|}
\hline [ku.í] & [kwí] & [Ø] & [Ø] & cui \\
\hline
\end{tabular}

Con esta posibilidad de diferenciación gráfica, la ortografía cumple otro de sus principios por los que se rige el sistema de acentuación gráfica del español: «A cada acentuación prosódica le corresponde una única representación gráfica acentual, y viceversa».

La alternancia cuy - cui, que refleja dos posiciones del acento dentro de una misma secuencia vocálica, se asemeja a la variación que presentaban palabras como amoníaco-amoniaco, díodo-diodo...

Constituye un caso discordante con esta regla el adverbio muy. «Es excepción el adverbio muy, escrito tradicionalmente con $y$, aunque su pronunciación general sea [muí] (v. cap. I, $\S$ 6.1.2.1.2b)]» (OLE10, §3.2: 218). Su articulación es variable: 


\begin{tabular}{|l|l|l|l|l|}
\hline [mu.í] & [mwíl & [mú.i] & [múi] & muy \\
\hline
\end{tabular}

\subsection{Secuencia vocálica /iu/}

\subsubsection{Variedad articulatoria}

La inestabilidad entre la realización diptongo $\sim$ hiato, así como en la distinta posición del acento, afecta también a las secuencias /iu/. El Esbozo se hacía eco de esta variabilidad:

El gupo /i u/ es más inestable en español. El diptongo acentuado /iú/ aparece en muy pocas palabras: triun-fo, por-ciún-cula. Algunas palabras vacilan, en mayor o menor grado, entre el diptongo /iú/ y el hiato /i.ú/: baquiuro, friura, diurno, oriundo, veintiuno, viuda. En la pronunciación de viuda se oye algunas veces el diptongo /íu/ que conserva el acento en la vocal silábica originaria y con el cual varía libremente en algunos territorios. El diptongo /íu/ se encuentra, además, en palabras americanas procedentes de lenguas indígenas: mañíu, síu, y con él se pronuncian topónimos y patronímicos catalanes que son de algún uso en español: Viu, Feliu, Bordiu, Rius, etcétera. Tanto el diptongo /iu/ como el hiato /í.u/ inacentuados se encuentran siempre delante del acento de la palabra: ciu-dad, viu-dedad, triun-fante, triun-fador, di-uresis, bi-unívoco, boqui-hundido, con tendencia del hiato a convertirse en diptongo ( RAE, 1973: § 1.4.11g).

\subsubsection{Fonología de las secuencias vocálicas /iu/}

\subsubsection{Posición tónica no final}

Cuando el acento recae en la sílaba que contiene la secuencia -iu- nos hallamos ante la misma situación que presentaban las secuencias -ui- en el interior de palabra: no es pertinente ni la forma de silabación (diptongo o hiato) ni la posición del acento (sobre la /i/ o sobre la /u/). Las sustituciones que refleja el cuadro 
siguiente nos muestran que estos dos rasgos no son diferenciadores y, por lo tanto, no son relevantes desde el punto de vista fonológico. En el habla de cada individuo o en la norma de algunas comunidades, o en la historia, puede predominar una de las cuatro posibilidades; pero eso no altera el valor del sistema, la distintividad:

\begin{tabular}{|c|c|c|c|c|}
\hline \multicolumn{2}{|c|}{ A (hiato) } & \multicolumn{2}{|c|}{ B (diptongo) } & \multirow[t]{2}{*}{ Ortografía } \\
\hline [í.u] & [i.ú] & [jú] & [íún] & \\
\hline [bí.uda] & [bi.úda] & [bjúda] & [bíunda] & viuda \\
\hline [dí.urno] & [di.úrno] & [djúrno] & [díunrno] & diurno \\
\hline [demí.urgo] & [demi.úrgo] & [demjúrgo] & [demíunrgo] & demiurgo \\
\hline [trí.unfo] & [tri.únfo] & [trjúnfo] & [tríunnfo] & triunfo \\
\hline [orí.undo] & [ori.úndo] & [orjúndo] & [oríundo] & oriundo \\
\hline [frí.ura] & [fri.úra] & [frjúra] & [fríunra] & friura \\
\hline [beintí.uno] & [beinti.úno] & [beintjúno] & [beintíunno] & veintiuno \\
\hline [fí.uঔia] & [fi.úજia] & [fjúજia] & [fíư⿱⿴囗十)] & fiucia \\
\hline [sí.uks] & [si.úks] & [sjúks] & [síunks] & $\sin x$ \\
\hline
\end{tabular}

La ortografía no distingue lo que la fonología no diferencia. En las combinaciones de vocal abierta y vocal cerrada era pertinente la posición del acento en una de las dos vocales (confío/ confió, acentúo/acentuó). Pero en las secuencias tónicas de dos vocales cerradas en el interior, al no ser relevante la posición del acento, la ortografía no lo distingue. Así, se escribe viuda, diurno, demiurgo, oriundo, friura... cualquiera sea la pronunciación. Solo aparece la tilde en la / $\mathrm{u} /$ cuando la sílaba ha de llevarla en cumplimiento de las reglas de acentuación: demiúrgico (por ser esdrújula, en este caso).

\subsubsection{Posición átona no final}

Cuando la secuencia vocálica -iu- se halla en una sílaba átona no final, cualquiera sea la base de su formación ${ }^{39}$, tiende a realizarse como diptongo creciente: ciu.dad, ciu.dadano, viu.dedad, triun.fal, triun.fante, triun.fador, diu.resis (formado sobre di-ure-

39 La denominada frontera morfológica tampoco es relevante en estos casos. 
sis), biu.nívoco (de bi-unívoco), bo.quihun.dido (de boqui-hundido), se.mium.broso (de semi-umbroso), pe.riur.bano (de peri-urbano), cua. siu.niversal (de cuasi-universal), triunviro...

\subsubsection{Posición tónica final}

El español tiene algunas palabras terminadas en el diptongo tónico /iu/. Se detecta una tendencia a acentuar el segundo elemento que se manifiesta sobre todo en las incorporaciones léxicas realizadas modernamente desde otras lenguas. Así ocurre con interviú (del ing. interview), el apellido Bordiú.

Pero existen otras voces que, generalmente por el contacto con la lengua de origen, acentúan prioritariamente la /i/: los árboles teniu y mañiu, el pájaro cantor $s i u$, $d i u^{40}$, algunas articulaciones de la plaga mildiu y otros acrónimos, los apellidos y topónimos de origen catalán (Viu, Riu, Feliu, Espriu, Guiu), el topónimo asturiano Partarri $u^{41}$. En el siguiente cuadro se reflejan en negrita las pronunciaciones más frecuentes y entre paréntesis las menos comunes:

La situación no difiere mucho de la que se presentaba con la secuencia tónica /ui/ en posición final de palabra: voces que acentúan la primera vocal y palabras que intensifican la segunda. Pero allí la ortografía ofrecía la posibilidad de manifestar esta diferencia:

- Uso de la letra " $\mathrm{i}$ " si representa la vocal tónica: construí, derruí, alauí, benjuí, hui, frui...

- Empleo de la letra "y" si la vocal que representa es átona: сосиy, Espeluy, tepuy, huy...

40 Acrónimo de dispositivo intrauterino.

41 Partarríu es el nombre de un palacete asturiano ubicado cerca de Llanes donde se han rodado varias películas. En asturiano abundan términos que finalizan en /íu/. Cuando aparecen intercalados en discursos en español, lo hacen con la acentuación propia: críu, tíu, fíu, ríu, partíu, queríu, fríu... 


\begin{tabular}{|c|c|c|c|}
\hline \multicolumn{2}{|c|}{ A (hiato) } & \multicolumn{2}{|c|}{ B (diptongo) } \\
\hline [í.u] & [i.ú] & [jú] & [íú \\
\hline [mildí.u] & [mildi.ú] & [mildjú] & [mildíun] \\
\hline [kodorní.u] & [kodorni.ú] & [kodornjú] & [kodorníun] \\
\hline ([interbí.u]) & [interbi.ú] & [interbjú] & ([interbíúl) \\
\hline ([bordí.u]) & [bordi.ú] & [bordjú] & ([bordíun]) \\
\hline [mañí.u] & ([mañi.ú]) & ([mañjú]) & [mañíú] \\
\hline [tení.u] & ([teni.ú]) & ([tenjú] $]$ & [teníun] \\
\hline [felí.u] & ([feli.ú]) & ([feljú]) & [felíúu \\
\hline [esprí.u] & ([espri.ú]) & ([esprjú]) & [espríun] \\
\hline [partar̂í.u] & ([partar̂i.ú]) & ([partar̂jú]) & [partar̂íún] \\
\hline [sí.u] & ([si.ú]) & ([sjú]) & [síú] \\
\hline [dí.u] & ([di.ú]) & ([djú]) & [díun] \\
\hline [r̂́í.u] & ([r̂i.ú]) & ([rjóúu) & [r̂́úu \\
\hline [ĉ́í.u] & ([ĉi.ú]) & ([çjú] $)$ & [ĉ́úu \\
\hline [bí.u] & ([bi.ú]) & ([bjú]) & [bíun] \\
\hline
\end{tabular}

La ortografía del español carece de un recurso gráfico para representar la alternativa homóloga en el caso de la secuencia vocálica final /iu/ en posición tónica. Cabrían dos opciones ortográficas:

1) Acentuar la última vocal (mildiú, mañiú) cualquiera sea la pronunciación real.

2) Colocar la tilde en la vocal acentuada (interviú, pero mañíu).

Existen argumentos que apoyan tanto una solución como la otra. En favor de acentuar la última vocal se hallan las siguientes razones:

a) La ausencia de distintividad entre las cuatro posibilidades fónicas ([í.u], [i.ú], [jú], [íun]) permite una representación ortográfica única.

b) Los fonetistas observan la tendencia de desplazar el acento hacia la última vocal. Así ha ocurrido cuando se han castellanizado totalmente algunas palabras del inglés (interviú) o del catalán (el apellido Bordiú). 
Basada en estas razones y también, en aras de la unidad de la escritura, la OLE10 ha establecido pauta convencional de colocar la tilde sobre la segunda vocal (mildiú, teniú, mañiú...), exceptuados los monosílabos, que, por serlo, no llevan tilde (siu):

Esta doble posibilidad en la acentuación prosódica de las secuencias de dos vocales cerradas distintas no resulta nunca distintiva, pues no existen palabras que se opongan únicamente por esta característica. Por todo ello, para las secuencias de dos vocales cerradas distintas (/ui/, /iu/) que precisen llevar tilde según las reglas de acentuación, el sistema ortográfico ha establecido también una pauta convencional que impone la colocación de este signo sobre la segunda de las vocales (v. $\S 3.4 .2 .1 .3 b$ ), de acuerdo con la acentuación prosódica más general de estos grupos. Esta convención garantiza la unidad en la escritura de las palabras que contienen estas combinaciones de vocales. (OLE10, pág. 15).

\section{Conclusiones}

1) La ortografía definía los conceptos de diptongo, triptongo e hiato basándose en criterios prosódicos. El diptongo y el triptongo se definían como sucesiones de dos o de tres vocales que se articulaban en un mismo golpe de voz (y que, como consecuencia, pertenecían a una misma sílaba). El hiato era la combinación de dos vocales que pertenecían a diferentes sílabas.

2) La articulación fónica de dos vocales seguidas como diptongo o como hiato depende de varios factores: su intensidad (tónica o átona), ubicación en la palabra (pretónica o postónica: coetáneo, héroe), su situación en la frase (contexto de sinalefa o no: Odio aqueste invierno), tipo de registro en el que se inserta (familiar, coloquial... o solemne), la rapidez de ejecución, la variedad dialectal, las relaciones morfológicas de la palabra (confí.o-confi. amos).

3) La ortografía tiene como función esencial «garantizar y facilitar la comunicación escrita entre los usuarios de una lengua mediante el establecimiento de un código común para su repre- 
sentación gráfica» (OLE10: 15). La ortografía cumple «un papel esencial como factor de unidad, puesto que impone una representación gráfica uniforme y común por encima de las numerosas variantes de pronunciación existentes, debidas a factores geográficos, socioculturales e incluso individuales» (OLE10: 15).

3) Las secuencias de vocales constituyen uno de los principales espacios de mayor variación fónica, pues unas veces se realizan como diptongos, otras como hiatos. La ortografía persigue superar esta variación en pro de una representación unitaria y común.

4) La ortografía consigue este objetivo cuando aplica un criterio inmanente y define las nociones de diptongo, triptongo e hiato ortográficos con independencia de la articulación concreta que una secuencia vocálica pueda tener en el habla o en la norma de comunidades lingüísticas. La OLE99 fija cuáles son las combinaciones vocálicas que forman diptongo y cuáles las que constituyen un hiato. Para que exista diptongo, tiene que darse una de estas situaciones:

a) Que se sucedan una vocal abierta $(a, e, o)$ y una cerrada $(i, u), \mathrm{o}$ viceversa, siempre que la cerrada no sea tónica. $[\ldots]$

b) Que se combinen dos vocales cerradas $(i, u)$ distintas: $u i, i u$. $[\ldots]$ (OLE99: 43).

La OLE10 define los conceptos y los aplica de forma consecuente prohibiendo tildar monosílabos ortográficos (guion, truhan, Sion, lie...)

Diptongos ortográficos. Los diptongos son secuencias de dos vocales que forman parte de una misma sílaba. Con independencia de cómo se articulen realmente en cada caso, se consideran siempre diptongos a efectos ortográficos las siguientes combinaciones vocálicas... (OLE10: 235).

5) La noción de diptongo ortográfico se viene forjando en la doctrina académica desde las Nuevas normas de 1952. Entonces 
se aplicó este criterio a las secuencias /ui/ (fui, beduino, ruin, jesuita...) que tanta polémica y cambios de criterio habían causado:

La combinación ui se considerará p rá c t i c a m e $n$ te como diptongo en todos los casos (RAE, 1952: 20).

6) El mismo criterio se aplica en la OLE74 a secuencias vocálicas en posición postónica (fatuo, perpetuo, tenue...) que se realizan en la pronunciación unas veces como diptongo y otras como hiato. La RAE resuelve con criterio ortográfico:

Las terminaciones $u o, u a, u e$, cuando ninguna de sus vocales es tónica, se consideran siempre diptongo a efectos ortográficos, cualquiera sea su pronunciación real (OLE74, Cap. III, § 36e: 26).

7) La escritura alfabética se halla estrechamente relacionada con la fonología. La conexión entre estas dos disciplinas proporciona un fundamento teórico de las nociones de diptongo, triptongo e hiato ortográficos. El análisis fonológico de las secuencias vocálicas muestra estos hechos:

a) Que la lengua diferencia las secuencias en las que cambia de vocal la posición del acento: porfío/porfió, espíe/espié, actúo/actuó...

b) Que cuando el acento cae sobre la vocal abierta, la lengua no distingue la realización de diptongo o de hiato: por.fi.ó por.fió, es.pi.é es.pié, ac.tu.ó ac.tuó.

c) Que, en los casos problemáticos del tipo guion, truhan, Sion, lie, fie, riais..., el hecho de que en algunas zonas y situaciones se articule con hiato y en otras como diptongo no es relevante desde el punto de vista fonológico. Son variaciones de norma o de habla que no afectan al sistema, pues no cambia el sentido al variar la articulación de hiato a diptongo: gui.on guion, tru.han truhan, Si.on Sion, li.e lie...

d) Que el análisis en que se fundamentan las nociones de diptongo, triptongo e hiato ortográficos se basa en he- 
chos de sistema. Está por encima de las realizaciones individuales e incluso de norma. Gracias a eso, la nueva ortografía puede ofrecer pautas de escritura unitarias, comunes para todos los miembros de la comunidad hispanohablante.

8) El criterio de la analogía morfológica ha sido utilizado por la prosodia, al menos desde A. Bello, para defender la existencia de hiato o diptongo en determinadas palabras. En la voz cri.a.mos se proyecta el hiato de crí.a, mientras que cam.bia.mos se pronuncia con diptongo porque la forma simple cam.bia así lo hace. Se ha mostrado que el peso de la frontera morfológica no es ni distintivo ni general y que, por lo tanto, no puede ser tomado como criterio ortográfico.

9) La secuencia de dos vocales cerradas (/iu/, /ui/) presenta mayor inestabilidad que las combinaciones entre vocal cerrada y vocal abierta. Las variaciones fónicas buitre ([bú.i.tre] [bu.í.tre] $\sim$ [bwí.tre] [búi.tre]; [bí.uda] [bi.úda] [bjúda] [bíúda]) no alteran el significado. No es pertinente ninguno de los dos parámetros:

1) ni la diferencia diptongo/hiato,

2) ni el cambio de posición del acento.

10) En posición final de palabra aguda la articulación de la secuencia vocálica /ui/ presenta dos posibilidades: que la intensidad caiga sobre la /u/ o sobre la /i/. La ortografía diferencia esta alternativa: la pronunciación [úi] se transcribe con -y: cocuy, cuy, huy o tepuy. Por el contrario, en la articulación [uí], el fonema /i/ final se escribe con $i$ : alauí, benjuí, tui o cui.

\section{Bibliografía}

Álvarez de Miranda, Pedro (2014) «La tilde en los demostrativos y en solo», Rinconete, Instituto Cervantes, abril de 2014, recogido en Álvarez de Miranda, Pedro (2016), Más que palabras, Madrid, Galaxia Gutenberg, págs. 240-245. 
Álvarez de Miranda, Pedro (2014) «Diptongos ortográficos (a vueltas con guión y guion)», Rinconete, Centro Virtual Cervantes, recogido en Álvarez de Miranda, Pedro (2016), Más que palabras, Madrid, Galaxia Gutenberg, págs. 226-233.

Bello, Andrés (1835) Principios de ortología y métrica de la lengua castellana, Imprenta de la Opinión, Santiago de Chile. (http://www.cervantesvirtual.com/obra/estudios-filologicos-tomo-1-principios-de-la-ortologia-y-metrica-de-la-lengua-castellana-y-otros-escritos).

CARo, Miguel Antonio (1980 [1887]) Notas a la “Ortología y métrica" de don Andrés Bello, Bogotá, Instituto Caro y Cuervo.

Casares, Julio (1951) «Problemas de Prosodia y Ortografía en el Diccionario y en la Gramática», $B R A E$, 31, págs. 371-452, y $B R A E, 32$, págs. 7-26.

CAsARES, Julio (1952) INFORME, incluido en RAE (1952), págs. 25-112. En nota se especifica: «Presentado a la R. Academia Española en la Junta de 8 de noviembre de 1951 por el académico D. Julio Casares». ApÉNDICE al informe precedente, incluido en RAE (1952), págs. 113-119.

Coseriu, Eugenio (1967) «Sistema, norma y habla», Teoría del lenguaje y Lingüística general. Madrid, Gredos.

Gil Fernández, Juana (1988) Los sonidos del lenguaje, Madrid, Síntesis.

Gómez Torrego, Leonardo (2013) «Comentarios a algunos cambios normativos recientes de la Real Academia Española y de la Asociación de Academias de la Lengua Española y la previsión de futuros cambios», Español Actual, 100, págs. 59-85.

Hidalgo Navarro, Antonio; Quilis Merín, Mercedes (2002) Fonética y fonología españolas, Valencia, Tirant lo Blanc.

Madsen, John Kuhlmann; Canellada, María Josefa (1987) Pronunciación del español, Madrid, Ed. Castallia.

Marías, Javier (2011) «Discusiones ortográficas», El País, 29/01/2011.

Medina SÁnchez, José Gerardo (2007) Tratado de los monosílabos. Los monosílabos como términos no segmentados del idioma espa- 
ñol, estudio morfosintáctico. Teoría y Práctica. Fondo Editorial de la Universidad Antenor Orrego, Trujillo, Perú.

Navarro Tomás, Tomás (1925) «Palabras sin acento», RFE XII, Cuaderno 4, págs. 335-375.

Navarro Tomás, Tomás $\left(1990^{24}\right)$ Manual de pronunciación española, Madrid, CSIC.

RAE (1742) Orthographia española, ed. facsímil, 2014, Madrid, Real Academia Española.

RAE (1952) Nuevas normas de prosodia y ortografía, Madrid, Imprenta S. Aguirre Torre.

RAE (1959) Nuevas normas de prosodia y ortografía, declaradas de aplicación preceptiva desde $1^{\circ}$ de enero de 1959, Madrid.

RAE (1969) (cit. OLE69) Ortografía. Publicación que incorpora al texto tradicional las Nuevas Normas declaradas de aplicación preceptiva desde $1^{o}$ de enero de 1959, Madrid, Imprenta Aguirre.

RAE (1974) (cit. OLE74) Ortografía. Publicación que incorpora al texto tradicional las Nuevas Normas declaradas de aplicación preceptiva desde $1^{\underline{o}}$ de enero de 1959, Segunda edición corregida y aumentada, Madrid, Imprenta Aguirre.

RAE-ASALE (1999) (cit. OLE99) Ortografía de la lengua española, Madrid, Espasa.

RAE-ASALE (2005) (cit. DPD) Diccionario panhispánico de dudas, Madrid, Santillana.

RAE-ASALE (2009) (cit. NGDLE09) Nueva gramática de la lengua española, Madrid, Espasa.

RAE-ASALE (2010) (cit. OLE10) Ortografía de la lengua española, Madrid, Espasa.

RAE-ASALE (2011) (cit. NGLEFF) Nueva gramática de la lengua española. Fonética y fonología, Madrid, Espasa. 
